Supporting Information

\title{
Bichalcogenophene Imide-Based Homopolymers: Chalcogen Atom Effects on the Optoelectronic Property and Device Performance in Organic Thin-Film Transistors
}

Shengbin Shi, ${ }^{\dagger, l}$ Linjing Tang,,${ }^{\dagger, l}$ Han Guo, ${ }^{\dagger}$ Mohammad Afsar Uddin, ${ }^{\ddagger}$ Hang Wang, ${ }^{\dagger}$ Kun Yang,,${ }^{\dagger}$ Bin Liu,${ }^{\dagger}$ Yingfeng Wang,${ }^{\dagger}$ Huiliang Sun,${ }^{\dagger}$ Han Young Woo,$\ddagger$ and Xugang Guo $*, \dagger$

$\uparrow$ Department of Materials Science and Engineering and The Shenzhen Key Laboratory for Printed Organic Electronics, Southern University of Science and Technology (SUSTech), No. 1088, Xueyuan Road, Shenzhen, Guangdong 518055, China

$\$$ Department of Chemistry, College of Science, Korea University, 145 Anam-ro, Seongbuk-gu, Seoul 02841, Republic of Korea

Keywords: imide, chalcogen atom, homopolymer, electron transport, organic thin-film transistor

\section{Table of Contents}

1. Materials and Instruments

2. Chemical synthesis

3. OTFT fabrication and characterization

4. UV-vis absorption spectra of polymer solutions

5. Thermal properties of monomers and polymers

6. DFT computation

6. OTFT performance of polymers

7. 2D-GIWAX data of polymer films.

8. NMR and HRMS spectra 


\section{Materials and instruments.}

All reagents, chemicals, and solvents were commercially available and were used without further treatment unless otherwise stated. Anhydrous tetrahydrofuran (THF), ethyl ether $\left(\mathrm{Et}_{2} \mathrm{O}\right)$, and toluene were distilled from sodium/benzophenone under nitrogen flow. ${ }^{1} \mathrm{H}$ NMR and ${ }^{13} \mathrm{C}$ NMR spectra were recorded on Bruker Ascend spectrometers. Elemental analyses were performed on Vario EL CUBE elemental analyzer. High resolution mass spectrometry (HRMS) data were collected on Thermo Scientific Q-Exactive equipment. GC-MS data were recorded on an Agilent technologies 7890B GC with 5977A MSD. Polymer molecular weights were measured on Polymer Laboratories GPC-PL220 high temperature GPC/SEC system vs polystyrene standards using 1,2,4-trichlorobenzene as the eluent at $150^{\circ} \mathrm{C}$. Differential scanning calorimetry (DSC) curves were collected on a differential scanning calorimetry (Mettler, STARe, $10{ }^{\circ} \mathrm{C} \min ^{-1}$, nitrogen eluent) and thermogravimetric analysis (TGA) curves were recorded on a TA Instrument (Mettler, STARe). UV-vis spectra of solution and film of small molecules and polymers at room temperature were collected on a Shimadzu UV-3600 UV-VIS-NIR spectrophotometer. High temperature UV-vis absorption spectra of polymer solutions were recorded on equipment of Perkin Elmer UV/VIS/NIR Spectrometer Lambda 950. Cyclic voltammetry measurements of small molecules and polymers were carried out under nitrogen atmosphere using a CHI760 Evoltammetric analyzer with $0.1 \mathrm{M}$ $(n-\mathrm{Bu})_{4} \mathrm{~N}^{+} \mathrm{PF}_{6}-$ in acetonitrile as the supporting electrolyte, a platinum disk working electrode, a platinum wire counter electrode, and a silver wire reference electrode were employed, the ferrocene/ferrocenium redox couple was used as the internal reference with a scanning rate of $50 \mathrm{mV}$ $\mathrm{s}^{-1}$. AFM measurements of polymer thin films were conducted using a Dimension Icon Scanning Probe Microscope (Asylum Research, MFP-3D-Stand Alone) in tapping mode. 2D-GIWAXS measurements were carried out at the PLS-II 9A U-SAXS beam line of Pohang Accelerator Laboratory, Korea. 


\section{Chemical synthesis.}
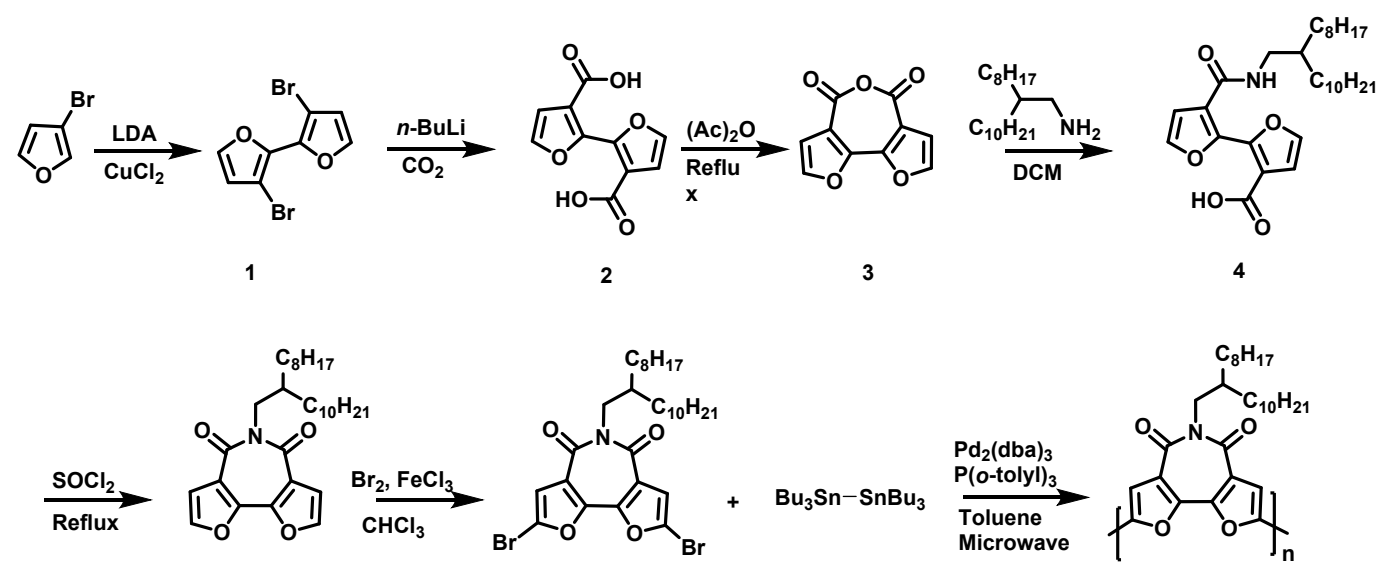

BFI

$\mathrm{BFI}-\mathrm{Br}$

PBFI

Scheme S1. Synthetic route to the dibrominated monomer BFI-Br and the corresponding homopolymer PBFI.

2,2'-Bifuran-3,3'-dicarboxylic Acid (2). 3,3'-Dibromo-2,2'-bifuran(1) was prepared according to the method reported in literature. ${ }^{1}$ Compound 1 ( $1.0 \mathrm{~g}, 3.43 \mathrm{mmol}, 1.0$ equiv.) was dissolved in 25 $\mathrm{mL}$ anhydrous $\mathrm{Et}_{2} \mathrm{O}$ in a three-necked flask under an argon atmosphere. The reaction solution was cooled to $-78{ }^{\circ} \mathrm{C}$ using an dry ice/acetone cooling bath. Then $3.42 \mathrm{~mL} n$-BuLi $(2.4 \mathrm{M}$ in hexane, $8.22 \mathrm{mmol}, 2.4$ equiv.) was added dropwise, and the reaction was then stirred at $-78{ }^{\circ} \mathrm{C}$ for $1.5 \mathrm{~h}$. Dry carbon dioxide $\left(\mathrm{CO}_{2}\right)$ was bubbled into the reaction mixture for $0.5 \mathrm{~h}$, and then stirred for an additional $0.5 \mathrm{~h}$ at $-78{ }^{\circ} \mathrm{C}$. The reaction mixture was gradually warmed to room temperature and stirred for $2 \mathrm{~h}$. To the reaction mixture was added $5 \mathrm{~mL}$ water, followed by the removal of solvent under reduced pressure. To the residue was added $\sim 25 \mathrm{~mL} 2 \mathrm{M} \mathrm{HCl}$ to acidify the salt and the precipitates were collected by filtration to afford the compound $\mathbf{2}$ as a yellow powder $(0.68 \mathrm{~g}, 90 \%)$. ${ }^{1} \mathrm{H}$ NMR (500 MHz, DMSO-d 6 ) $\delta 12.78$ (br, 2H), 7.90 (d, $\left.J=1.9 \mathrm{~Hz}, 2 \mathrm{H}\right), 6.85$ (d, $\left.J=1.9 \mathrm{~Hz}, 2 \mathrm{H}\right)$. ${ }^{13} \mathrm{C}$ NMR (125 MHz, DMSO-d 6 ) $\delta 163.32,144.62,142.40,120.16,112.06$. HRMS (ESI, m/z): calcd for $\mathrm{C}_{10} \mathrm{H}_{7} \mathrm{O}_{6}[\mathrm{M}+\mathrm{H}]^{+}: 223.02371$, found: 223.02306 .

2,2'-Bifuran-3,3'-dicarboxylic anhydride (3). ${ }^{2}$ Compound $2(0.91 \mathrm{~g}, 4.096 \mathrm{mmol})$ was dissolved in $25 \mathrm{~mL}$ acetic anhydride, and then stirred under reflux for overnight. After cooled to $0{ }^{\circ} \mathrm{C}$, the solid was collected by filtration and then dried in vacuo at $70{ }^{\circ} \mathrm{C}$ to afford a yellow solid as the product 3 $(0.79 \mathrm{~g}, 95 \%)$, which was directly used for the next step without further purification.

$N$-(2-octyldodecyl)-2,2'-bifuran-3,3'-dicarboximide (BFI). ${ }^{2}$ A solution of 2-octyldodecylamine (0.64 g, $2.14 \mathrm{mmol}, 1.0$ equiv.) in $25 \mathrm{~mL}$ dichloromethane (DCM) was added dropwise to a solution 
of compound 3 (0.44 g, $2.14 \mathrm{mmol}, 1.0$ equiv.) in $30 \mathrm{~mL}$ DCM. After addition, the reaction mixture was stirred under reflux for $2 \mathrm{~h}$. Upon the removal of solvent, the residue oil 4 was obtained. The compound 4 was dissolved in $10 \mathrm{~mL}$ thionyl chloride, and the mixture was refluxed for $50 \mathrm{~min}$. Then the thionyl chloride was removed using vacuum evaporation. The residual oil was purified by column chromatography using petroleum(PE):DCM (10 3:1) as the eluent to afford a white solid $(0.57 \mathrm{~g}, 55 \%) .{ }^{1} \mathrm{H}$ NMR $\left(400 \mathrm{MHz}, \mathrm{CDCl}_{3}\right) \delta 7.54(\mathrm{~d}, J=1.2 \mathrm{~Hz}, 2 \mathrm{H}), 7.16(\mathrm{~d}, J=1.1 \mathrm{~Hz}, 2 \mathrm{H}), 4.24$ $(\mathrm{d}, J=7.2 \mathrm{~Hz}, 2 \mathrm{H}), 1.91-1.87(\mathrm{~m}, 1 \mathrm{H}), 1.41-1.15(\mathrm{~m}, 32 \mathrm{H}), 0.91-0.82(\mathrm{~m}, 6 \mathrm{H}) .{ }^{13} \mathrm{C}$ NMR $(100$ $\left.\mathrm{MHz}, \mathrm{CDCl}_{3}\right) \delta 160.87,143.61,143.45,120.44,114.37,48.59,36.47,32.06,32.03,31.88,30.21$, 29.77, 29.74, 29.69, 29.47, 29.44, 26.67, 22.80, 14.23. HRMS (ESI, m/z): calcd for $\mathrm{C}_{30} \mathrm{H}_{46} \mathrm{NO}_{4}$ $[\mathrm{M}+\mathrm{H}]^{+}:$484.34214, found: 484.34134 .

$N$-(2-octyldodecyl)-5,5'-dibromo-2,2'-bifuran-3,3'-dicarboximide (BFI-Br). ${ }^{2}$ Bromine (0.55 g, 3.44 mmol, 2.5 equiv.) was added to a solution of the imide BFI (0.67 g, $1.38 \mathrm{mmol}, 1.0$ equiv.) in $25 \mathrm{~mL}$ DCM. To the mixture was then added anhydrous $\mathrm{FeCl}_{3}(7.0 \mathrm{mg}, 0.043 \mathrm{mmol}, 0.03$ equiv). The reaction mixture was allowed to stir under dark for $1 \mathrm{~h}$, and then $15 \mathrm{~mL} \mathrm{Na} \mathrm{SO}_{3}$ aqueous solution was added and stirred for $10 \mathrm{~min}$. The reaction mixture was poured into $100 \mathrm{~mL}$ DCM, and the organic layer was washed several times with water. After the removal of solvent, the combined organic layer afforded a residual oil, which was purified over column chromatography using PE:DCM (10-3: 1) as the eluent to provide a white solid as the product $(0.52 \mathrm{~g}, 58 \%) .{ }^{1} \mathrm{H}$ NMR $(500$ $\left.\mathrm{MHz}, \mathrm{CDCl}_{3}\right) \delta 7.07(\mathrm{~s}, 2 \mathrm{H}), 4.20(\mathrm{~d}, J=7.3 \mathrm{~Hz}, 2 \mathrm{H}), 1.86^{-1.81}(\mathrm{~m}, 1 \mathrm{H}), 1.38^{-1.14}(\mathrm{~m}, 32 \mathrm{H})$, 0.91-0.84 (m, 6H). ${ }^{13} \mathrm{C}$ NMR $\left(125 \mathrm{MHz}, \mathrm{CDCl}_{3}\right) \delta 159.49,143.45,126.10,121.91,115.85,48.74$, $36.35,32.07,32.05,31.76,30.18,29.79,29.74,29.70,29.50,29.46,26.59,22.84,22.82,14.28$. HRMS (ESI, m/z): calcd for $\mathrm{C}_{30} \mathrm{H}_{44} \mathrm{Br}_{2} \mathrm{NO}_{4}[\mathrm{M}+\mathrm{H}]^{+}$: 642.16111, found: 642.15881. Elem. Anal. Calcd for $\mathrm{C}_{30} \mathrm{H}_{43} \mathrm{Br}_{2} \mathrm{NO}_{4}(\%)$ : C, 56.17; H, 6.76; N, 2.18. Found (\%): C, 56.34; H, 6.87; N, 2.11 .

Poly(N-(2-octyldodecyl)-2,2'-bifuran-3,3'-dicarboximide (PBFI). ${ }^{3}$ To a $5 \mathrm{~mL}$ microwave tube was charged compound BFI-Br (136.3 mg, $0.2125 \mathrm{mmol}$ ), bis(tributyltin) (123.3 mg, $0.2125 \mathrm{mmol}$ ), tri(o-tolyl)phosphine (10.3 mg, $12 \mathrm{~mol} \%$ ), tris(dibenzylideneacetone)dipalladium(0) (3.9 mg, 1.5 mol\%), and $3.5 \mathrm{~mL}$ anhydrous toluene under nitrogen atmosphere. The microwave tube was sealed and then stirred at $80{ }^{\circ} \mathrm{C}$ for 10 minutes, $100^{\circ} \mathrm{C}$ for 10 minutes, and $140{ }^{\circ} \mathrm{C}$ for $4 \mathrm{~h}$ under microwave irradiation. The reaction mixture was dripped into $150 \mathrm{~mL}$ methanol containing $3 \mathrm{~mL}$ hydrochloric acid under vigorous stirring. After stirring for $20 \mathrm{~min}$, the polymer precipitates were transferred to a Soxhlet thimble. The crude polymer was subjected to sequential Soxhlet extraction with methanol, 
acetone, and hexane as the solvents. The extracted polymer in hexane was concentrated to $\sim 8 \mathrm{~mL}$, and then dripped into $200 \mathrm{~mL}$ methanol. The polymer was collected by filtration and dried under reduced pressure to afford an orange solid as the product polymer (50.6 mg, 50\%). ${ }^{1} \mathrm{H}$ NMR (400 $\left.\mathrm{MHz}, 80^{\circ} \mathrm{C}, \mathrm{C}_{2} \mathrm{D}_{2} \mathrm{Cl}_{4}\right): \delta 7.75^{-7.40}(\mathrm{~m}, 2 \mathrm{H}), 4.52-4.20(\mathrm{~m}, 2 \mathrm{H}), 2.10^{-1.89}(\mathrm{~m}, 1 \mathrm{H}), 1.44-1.12(\mathrm{~s}$, 32H), 0.99-0.81 (m, 6H). Elem. Anal. Calcd for $\mathrm{C}_{30} \mathrm{H}_{43} \mathrm{NO}_{4}(\%)$ : C, 74.81; H, 9.00; N, 2.91. Found (\%): C, 74.45; H, 9.07; N, 2.76. HT-GPC: $\mathrm{M}_{\mathrm{n}}=7.0 \mathrm{kDa}, \mathrm{M}_{\mathrm{w}}=10.7 \mathrm{kDa}, \mathrm{PDI}=1.52$.
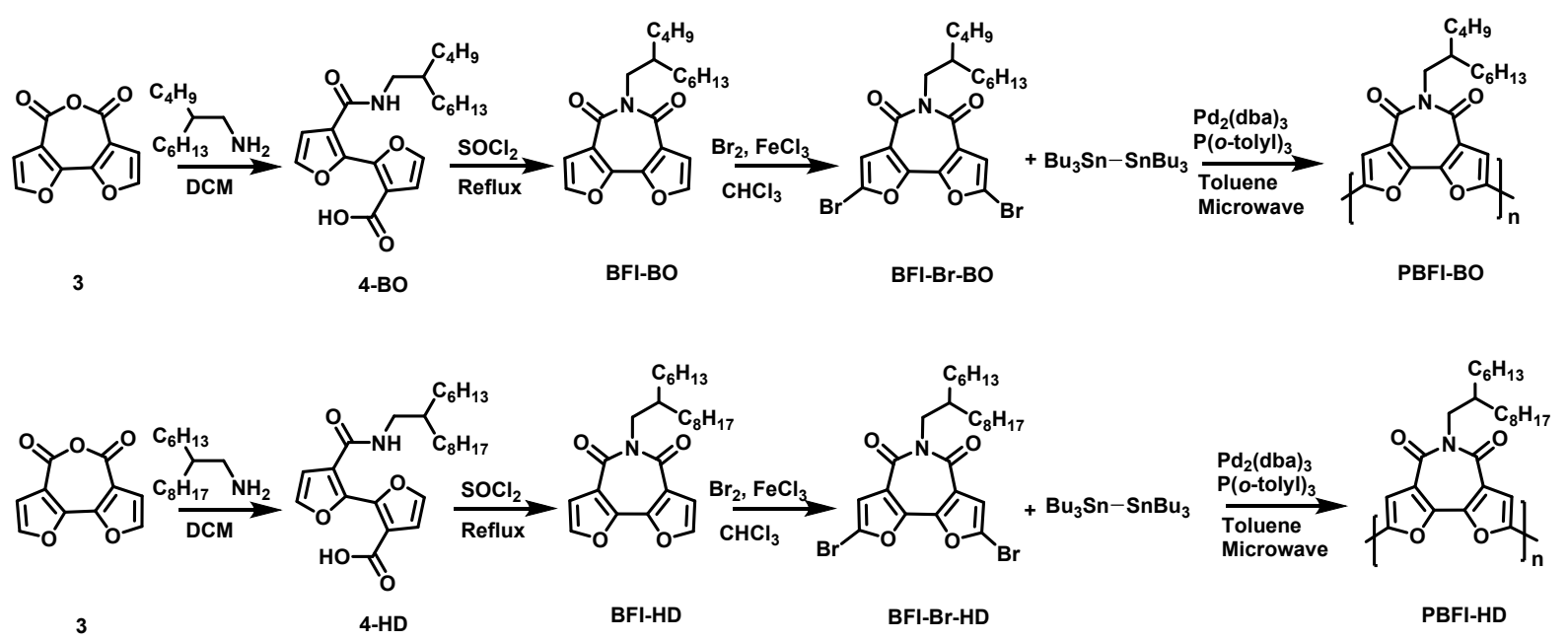

Scheme S2. Synthetic route to the bifuran imide homopolymers PBFI-BO and PBFI-HD with a 2-butyloctyl and 2-hexyldecyl side chain, respectively.

N-(2-butyloctyl)-2,2'-bifuran-3,3'-dicarboximide (BFI-BO). The synthesis procedure of BFI-BO is the same as that used for BFI. A white solid was obtained as the product (yield: $72 \%$ ). ${ }^{1} \mathrm{H}$ NMR $\left(400 \mathrm{MHz}, \mathrm{CDCl}_{3}\right) \delta 7.55(\mathrm{~d}, J=1.9 \mathrm{~Hz}, 2 \mathrm{H}), 7.16(\mathrm{~d}, J=1.8 \mathrm{~Hz}, 2 \mathrm{H}), 4.24(\mathrm{~d}, J=7.3 \mathrm{~Hz}, 2 \mathrm{H})$, 1.91-1.84 (m, 1H), 1.38-1.17 (m, 16H), 0.91-0.82 (m, 6H). ${ }^{13} \mathrm{C}$ NMR (100 MHz, $\left.\mathrm{CDCl}_{3}\right) \delta 160.89$, $143.64,143.44,120.42,114.35,48.54,36.45,31.97,31.84,31.53,29.89,28.86,26.62,23.25,22.78$, 14.22 .

N-(2-butyloctyl)-5,5'-dibromo-2,2'-bifuran-3,3'-dicarboximide (BFI-Br-BO). The synthesis procedure of BFI-Br-BO is the same as that used for BFI-Br. A white solid was obtained as the product (yield: 88\%). ${ }^{1} \mathrm{H}$ NMR (500 MHz, $\left.\mathrm{CDCl}_{3}\right) \delta 7.07(\mathrm{~s}, 2 \mathrm{H}), 4.20(\mathrm{~d}, J=7.2 \mathrm{~Hz}, 2 \mathrm{H})$, $1.88-1.79(\mathrm{~m}, 1 \mathrm{H}), 1.38-1.16(\mathrm{~m}, 16 \mathrm{H}), 0.90^{-0} 0.82(\mathrm{~m}, 6 \mathrm{H}) .{ }^{13} \mathrm{C} \mathrm{NMR}\left(125 \mathrm{MHz}, \mathrm{CDCl}_{3}\right) \delta 159.48$, $143.44,126.09,121.90,115.84,48.70,36.36,31.97,31.75,31.43,29.87,28.78,26.56,23.23,22.79$, 14.24. HRMS (ESI, m/z): calcd for $\mathrm{C}_{22} \mathrm{H}_{28} \mathrm{Br}_{2} \mathrm{NO}_{4}[\mathrm{M}+\mathrm{H}]^{+}: 530.03591$, found: 530.03589 .

Poly(N-(2-butyloctyl)-2,2'-bifuran-3,3'-dicarboximide (PBFI-BO). The synthesis procedure of PBFI-BO is the same as that used for PBFI. An orange solid was obtained as the product (yield: 
47\%). HT-GPC: $\mathrm{M}_{\mathrm{n}}=8.9 \mathrm{kDa}, \mathrm{M}_{\mathrm{w}}=11.7 \mathrm{kDa}$, PDI $=1.16$.

N-(2-hexyldecyl)-2,2'-bifuran-3,3'-dicarboximide (BFI-HD). The synthesis procedure of BFI-HD is the same as that used for BFI. A white solid was obtained as the product (yield: $53 \%$ ). ${ }^{1} \mathrm{H} \mathrm{NMR}$ $\left(400 \mathrm{MHz}, \mathrm{CDCl}_{3}\right) \delta 7.54(\mathrm{~d}, J=1.2 \mathrm{~Hz}, 2 \mathrm{H}), 7.16(\mathrm{~d}, J=1.1 \mathrm{~Hz}, 2 \mathrm{H}), 4.24(\mathrm{~d}, J=7.2 \mathrm{~Hz}, 2 \mathrm{H})$, 1.91-1.84 (m, 1H), 1.40-1.16 (m, 24H), 0.89-0.80 (m, 6H). $\left.{ }^{13} \mathrm{C} \mathrm{NMR} \mathrm{(100} \mathrm{MHz,} \mathrm{CDCl}_{3}\right) \delta 160.87$, $143.61,143.46,120.45,114.37,48.60,36.49,32.03,31.97,31.92,30.20,29.88,29.68,29.43,26.67$, $26.64,22.79,14.21$.

$N$-(2-hexyldecyl)-5,5'-dibromo-2,2'-bifuran-3,3'-dicarboximide (BFI-Br-HD). The synthesis procedure of BFI-Br-HD is the same as that used for BFI-Br. A white solid was obtained as the product (yield: 63\%). ${ }^{1} \mathrm{H} \mathrm{NMR}\left(500 \mathrm{MHz}, \mathrm{CDCl}_{3}\right) \delta 7.07(\mathrm{~s}, 2 \mathrm{H}), 4.20(\mathrm{~d}, J=7.3 \mathrm{~Hz}, 2 \mathrm{H})$, 1.91-1.78 (m, 1H), 1.36-1.15 (m, 24H), 0.89-0.83 (m, 6H). ${ }^{13} \mathrm{C} \mathrm{NMR} \mathrm{(125} \mathrm{MHz,} \mathrm{CDCl} 3$ ) $\delta 159.49$, $143.45,126.10,121.91,115.85,48.74,36.37,32.04,31.97,31.79,31.74,30.18,29.87,29.69,29.45$, 26.58, 26.56, 22.82, 22.79, 14.26. HRMS (ESI, m/z): calcd for $\mathrm{C}_{26} \mathrm{H}_{36} \mathrm{Br}_{2} \mathrm{NO}_{4}[\mathrm{M}+\mathrm{H}]^{+}:$586.09851, found: 586.09918 .

$\operatorname{Poly}(N$-(2-hexyldecyl)-2,2'-bifuran-3,3'-dicarboximide (PBFI-HD). The synthesis procedure of PBFI-HD was the same as that used for PBFI. An orange solid was obtained as the product (yield: 42\%). HT-GPC: $\mathrm{M}_{\mathrm{n}}=5.0 \mathrm{kDa}, \mathrm{M}_{\mathrm{w}}=5.6 \mathrm{kDa}, \mathrm{PDI}=1.13$.
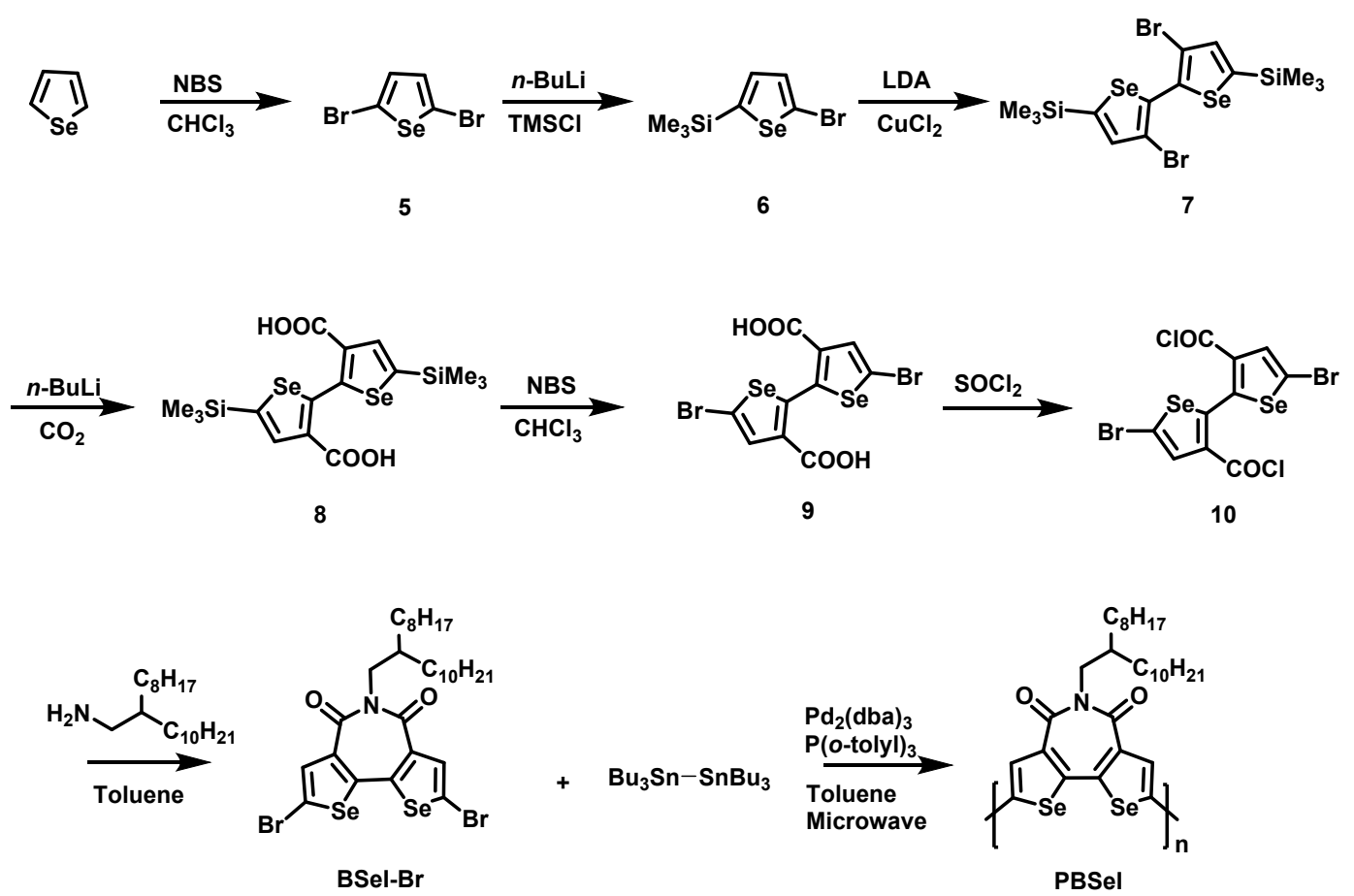

Scheme S3. Synthetic route to the dibrominated monomer BSeI-Br and the corresponding homopolymer.

2,5-Dibromoselenophene (5). ${ }^{4}$ Selenophene (25.0 g, $190.78 \mathrm{mmol}, 1.0$ equiv.) was dissolved in 640 
$\mathrm{mL} \mathrm{CHCl}_{3}$ and to the mixture was then added $N$-bromosuccinimide (74.0 g, $419.7 \mathrm{mmol}, 2.2$ equiv.) in several portions. After stirring at room temperature overnight, the reaction mixture was quenched with $\mathrm{Na}_{2} \mathrm{SO}_{3}$ (aq) solution, extracted with DCM three times. The combined organic layer was washed with water three times. The solvent was removed under vacuum and the residual oil was purified by column chromatography using PE as the eluent to provide a yellow oil as the product (42.5 g, 77\%). ${ }^{1} \mathrm{H}$ NMR (400 MHz, $\left.\mathrm{CDCl}_{3}\right) \delta 7.01(\mathrm{~s}, 2 \mathrm{H}) .{ }^{13} \mathrm{C}$ NMR $\left(100 \mathrm{MHz}, \mathrm{CDCl}_{3}\right) \delta 133.14$, 115.74. GC-MS (EI, m/z): calcd for $\mathrm{C}_{4} \mathrm{H}_{2} \mathrm{Br}_{2} \mathrm{Se}: 289.77$, found: 289.9 .

2-Bromo-5-(trimethylsilanyl)selenophene (6). ${ }^{4,5}$ To a solution of 5 (24.61 g, $85.2 \mathrm{mmol}, 1.0$ equiv.) in $380 \mathrm{~mL}$ dry $\mathrm{Et}_{2} \mathrm{O}$ was added $n$-BuLi (35.5 mL, $2.4 \mathrm{M}$ in hexane, $85.2 \mathrm{mmol}, 1.0$ equiv.) at $-78{ }^{\circ} \mathrm{C}$ dropwise. The mixture solution was stirred at $-78^{\circ} \mathrm{C}$ for $2 \mathrm{~h}$, then chlorotrimethylsilane (TMSCl) (16.2 mL, $13.88 \mathrm{~g}, 127.8 \mathrm{mmol}, 1.5$ equiv.) was added. The reaction mixture was gradually warmed to room temperature. After stirring overnight, the reaction mixture was quenched with water and extracted with DCM three times. The organic solvent was removed under vacuum and the residual oil was purified by column chromatography using PE as the eluent to provide a yellow oil as the product $(22.5 \mathrm{~g}, 94 \%) .{ }^{1} \mathrm{H}$ NMR $\left(400 \mathrm{MHz}, \mathrm{CDCl}_{3}\right) \delta 7.29(\mathrm{~d}, J=3.7 \mathrm{~Hz}, 1 \mathrm{H}), 7.21(\mathrm{~d}, J=3.7$ $\mathrm{Hz}, 1 \mathrm{H}), 0.29$ (s, 9H). ${ }^{13} \mathrm{C}$ NMR $\left(100 \mathrm{MHz}, \mathrm{CDCl}_{3}\right) \delta 137.70,136.53,134.67,119.88,0.27$. GC-MS (EI, m/z): calcd for $\mathrm{C}_{7} \mathrm{H}_{11} \mathrm{BrSeSi}$ : 281.90. Found: 281.9 .

3,3'-Dibromo-5,5'-bistrimethylsilyl-2,2'-biselenophene (7). ${ }^{6} n$-BuLi (27.5 mL, $2.4 \mathrm{M}$ in hexane, $66.0 \mathrm{mmol}, 1.0$ equiv.) was added dropwise to diisopropylamine $(11.17 \mathrm{~mL}, 8.01 \mathrm{~g}, 79.2 \mathrm{mmol}, 1.2$ equiv.) in $27 \mathrm{~mL} \mathrm{THF}$ at $-78{ }^{\circ} \mathrm{C}$. The mixture was then warmed to $0{ }^{\circ} \mathrm{C}$ for about $0.5 \mathrm{~h}$ to obtain fresh prepared LDA (1.0 M). The LDA solution $(63.8 \mathrm{~mL}, 63.8 \mathrm{mmol}, 1.2$ equiv.) was transferred by syringe into a solution of $6(15.0 \mathrm{~g}, 53.2 \mathrm{mmol}, 1.0$ equiv. $)$ in $450 \mathrm{~mL}$ dry $\mathrm{Et}_{2} \mathrm{O}$ at $-78{ }^{\circ} \mathrm{C}$. The mixture was stirred about $40 \mathrm{~min}$ at $-78^{\circ} \mathrm{C}$, then anhydrous $\mathrm{CuCl}_{2}(7.15 \mathrm{~g}, 53.8 \mathrm{mmol}, 1.0$ equiv.) was added to the reaction mixture. The resulting mixture was stirred for $2 \mathrm{~h}$ at $-78^{\circ} \mathrm{C}$ and then $2 \mathrm{~h}$ at room temperature. The reaction mixture was poured into $300 \mathrm{~mL}$ brine, extracted with $\mathrm{Et}_{2} \mathrm{O}$ for three times. The organic solvent was removed under vacuum evaporation and the residual yellow oil was purified by column chromatography using PE as the eluent to provide a light yellow solid as the product $(8.2 \mathrm{~g}, 55 \%) .{ }^{1} \mathrm{H}$ NMR $\left(500 \mathrm{MHz}, \mathrm{CDCl}_{3}\right) \delta 7.47(\mathrm{~s}, 2 \mathrm{H}), 0.34(\mathrm{~s}, 18 \mathrm{H}) .{ }^{13} \mathrm{C} \mathrm{NMR}(125$ $\left.\mathrm{MHz}, \mathrm{CDCl}_{3}\right) \delta 150.17,139.67,139.60,113.60,0.09$.

5,5'-Bistrimethylsilyl-2,2'-biselenophene-3,3'-dicarboxylic Acid (8). ${ }^{7}$-BuLi (2.69 mL, $2.4 \mathrm{M}$ in hexane, $6.45 \mathrm{mmol}, 2.4$ equiv.) was added dropwise to the compound 7 (1.51g, $2.69 \mathrm{mmol}, 1.0$ 
equiv.) in $100 \mathrm{~mL}$ dry $\mathrm{Et}_{2} \mathrm{O}$ at $-78{ }^{\circ} \mathrm{C}$. The reaction mixture was then allowed to stir for $30 \mathrm{~min}$ at $-78^{\circ} \mathrm{C}$ before dry $\mathrm{CO}_{2}$ was bubbled into it. After stirred at $-78{ }^{\circ} \mathrm{C}$ for $2 \mathrm{~h}$, the mixture was warmed to room temperature and $10 \mathrm{~mL}$ water was then added. Upon the removal of solvent, $15 \mathrm{~mL}$ hydrochloric acid was added to reaction mixture to acidify the salt and the precipitates were collected by filtration to afford the diacid as a pale yellow solid. This solid was dried in vacuo at 60 ${ }^{\circ} \mathrm{C}$ for overnight to give the product $(0.85 \mathrm{~g}, 64 \%) .{ }^{1} \mathrm{H}$ NMR (400 MHz, DMSO- $\left.d_{6}\right) \delta 12.70$ (br, 2H), $7.88(\mathrm{~d}, J=16.6 \mathrm{~Hz}, 2 \mathrm{H}), 0.32(\mathrm{~d}, J=3.7 \mathrm{~Hz}, 18 \mathrm{H})$. HRMS (ESI, m/z): calcd for $\mathrm{C}_{16} \mathrm{H}_{22} \mathrm{O}_{4} \mathrm{Se}_{2} \mathrm{Si}_{2}$ [M-H]": 492.93143. Found: 492.93121.

5,5'-Dibromo-2,2'-biselenophene-3,3'-dicarboxylic Acid (9). Compound 8 (1.79 g, 3.64 mmol, 1.0 equiv.) was dissolved in $50 \mathrm{~mL}$ chloroform, and then to the reaction was added $N$-bromosuccinimide (1.55 g, $8.73 \mathrm{mmol}, 2.4$ equiv.). After addition, the reaction was stirred at ambient condition overnight. To the solution was added $30 \mathrm{~mL}$ water and then extracted with DCM three times. The combined organic layer was dried over anhydrous sodium sulfate. After the filtration and removal of the solvent under reduced pressure, a yellowish solid was obtained the product $(1.38 \mathrm{~g}, 87 \%) .{ }^{1} \mathrm{H}$ NMR (400 MHz, DMSO-d $\left.d_{6}\right) \delta 11.06$ (br, 2H), 7.14 (d, $J=37.6$ Hz, 2H). HRMS (ESI, m/z): calcd for $\mathrm{C}_{9} \mathrm{H}_{3} \mathrm{Br}_{2} \mathrm{O}_{2} \mathrm{Se}_{2}\left[\mathrm{M}-\mathrm{CO}_{2}-\mathrm{H}\right]:$ : 460.68357. Found: 460.68335.

$N$-(2-Octyldodecyl)-5, 5'-dibromo-2,2'- biselenophene-3,3'-dicarboximide (BSeI-Br). ${ }^{8}$ A mixture of compound 10 (1.80 g, $3.56 \mathrm{mmol}, 1.0$ equiv.) in $45 \mathrm{~mL}$ thionyl chloride was heated to reflux overnight. The solvent was evaporated to afford a yellow solid 11. The product 11 in $40 \mathrm{~mL}$ anhydrous toluene was heated to reflux in a flask, and 2-octyldodecylamine (1.06 g, $3.56 \mathrm{mmol}, 1.0$ equiv.) in $20 \mathrm{~mL}$ toluene was then added dropwise. The reaction mixture was allowed to reflux for 2 $\mathrm{h}$ and then the solvent was removed to afford a yellow liquid. The crude product was further purified by column chromatography using PE:DCM as the eluent to give a pale yellow solid as the product (1.16 g, 43\%). ${ }^{1} \mathrm{H}$ NMR (500 MHz, $\left.\mathrm{CDCl}_{3}\right) \delta 7.90$ (s, 2H), 4.12 (d, J=7.2 Hz, 2H), 1.88-1.78 (m, 1H), 1.41-1.13 (m, 32H), 0.97-0.72 (m, 6H). ${ }^{13} \mathrm{C}$ NMR (125 MHz, $\left.\mathrm{CDCl}_{3}\right) \delta 162.03,145.75$, $138.71,135.01,115.52,50.35,36.44,32.08,32.07,31.72,30.18,29.81,29.75,29.70,29.52,29.48$, 26.51, 22.85, 14.29. HRMS (ESI, m/z): calcd for $\mathrm{C}_{30} \mathrm{H}_{44} \mathrm{Br}_{2} \mathrm{NO}_{2} \mathrm{Se}_{2}[\mathrm{M}+\mathrm{H}]^{+}:$768.00637, Found: 768.00299. Elem. Anal. Calcd for $\mathrm{C}_{30} \mathrm{H}_{43} \mathrm{Br}_{2} \mathrm{NO}_{2} \mathrm{Se}_{2}$ (\%): C, 46.95; H, 5.65; N, 1.83. Found (\%): C, 46.46; H, 5.67; N, 1.76 .

Poly(N-(2-octyldodecyl)-2,2'-biselenophene-3,3'-dicarboximide $\quad$ (PBSeI). ${ }^{3} \quad$ The $\quad$ synthesis procedure of PBSeI was the same as that used for PBFI. The product polymer was obtained as a 
black solid with a yield of $79 \% .{ }^{1} \mathrm{H} \mathrm{NMR}\left(400 \mathrm{MHz}, 80^{\circ} \mathrm{C}, \mathrm{C}_{2} \mathrm{D}_{2} \mathrm{Cl}_{4}\right) \delta 8.10^{-7.65}(\mathrm{~m}, 2 \mathrm{H})$, 4.44-4.05 (m, 2H), 2.02-1.87 (m, 1H), 1.68-1.21 (m, 32H), 1.05-0.83 (m, 6H). Elem. Anal. Calcd for $\mathrm{C}_{30} \mathrm{H}_{43} \mathrm{NO}_{2} \mathrm{Se}_{2}(\%)$ : C, 59.30; H, 7.13; N, 2.31. Found (\%): C, 59.42; H, 7.28; N, 2.35. Molecular weight: $M_{\mathrm{n}}=16.5 \mathrm{kDa}, M_{\mathrm{w}}=44.6 \mathrm{kDa}, \mathrm{PDI}=2.71$.

PBSeI*. In order to study the effect of polymer molecular weight on OTFT performance, a batch of PBSeI with a low molecular weight (designated as PBSeI*) was synthesized by decreasing the polymerization time and lowering the polymerization temperature. The microwave tube was stirred at $80{ }^{\circ} \mathrm{C}$ for 10 minutes, $100{ }^{\circ} \mathrm{C}$ for 10 minutes, and $120{ }^{\circ} \mathrm{C}$ for $1.5 \mathrm{~h}$ under microwave irradiation. The product polymer was obtained as a black solid with a yield of 55\%. Molecular weight: $M_{\mathrm{n}}=8.2$ $\mathrm{kDa}, M_{\mathrm{w}}=17.4 \mathrm{kDa}, \mathrm{PDI}=2.12$.

\section{OTFT fabrication and characterization.}

Top-gate/bottom-contact (TG/BC) organic thin-film transistors (OTFTs) were fabricated to probe the charge transport property of the PBXI-based polymers. Source and drain electrodes (30 $\mathrm{nm}$ gold with $3 \mathrm{~nm}$ chromium layer) were patterned on borosilicate glass by standard photolithography process with channel length of $10,20,50$, or $100 \mu \mathrm{m}$ and channel width of $5 \mathrm{~mm}$. The patterned substrates were cleaned by sonication in acetone for $10 \mathrm{~min}$, and then in isopropanol for $10 \mathrm{~min}$, followed by the UV-ozone treatment for $60 \mathrm{~min}$. The cleaned substrates were then moved into a nitrogen-filled glove box. Then CsF (Sigma Aldrich) electron injection layer was spin-coated from 2-ethoxymethanol solution $\left(2 \mathrm{mg} \mathrm{mL}^{-1}\right)$ and annealed at $120{ }^{\circ} \mathrm{C}$ for $30 \mathrm{~min}$. The polymer films were deposited from $5 \mathrm{mg} \mathrm{mL}^{-1}$ in chlorobenzene and 1,2-dichlorobenzene (o-DCB) solutions via spin-coating (1500 rpm $\left.\mathrm{min}^{-1}, 30 \mathrm{~s}\right)$, then thermally annealed at various temperatures $\left(100,150\right.$, and $200{ }^{\circ} \mathrm{C}$ ) for $30 \mathrm{~min}$ followed by cooling-down process. The CYTOP dielectric layer was spin-coated $\left(1500 \mathrm{rpm} \mathrm{min}^{-1}, 60 \mathrm{~s}\right)$ onto the semiconducting film from a solution (CTL-809M: CT-SOLV180 = 2: 1 , volume ratio), then thermally annealed $\left(100{ }^{\circ} \mathrm{C}, 20 \mathrm{~min}\right)$. Finally, $50 \mathrm{~nm} \mathrm{Al}$ was thermally evaporated on top as the gate electrode to complete the device fabrication under high vacuum.

The OTFT characterization was performed inside a nitrogen-filled glove box using the semiconductor analyzer (Keithley S4200). To calculate the electron mobility, the equation $I_{\text {sd }}=$ $\mu C_{\mathrm{i}}(W / 2 L)\left(V_{g}-V_{\mathrm{T}}\right)^{2}$ was used, wherein $I_{\mathrm{sd}}$ is the source/drain current, $\mu$ is the mobility, $C_{\mathrm{i}}$ is the dielectric capacitance, $W$ is the channel width, $L$ is the channel length, $V_{g}$ is the gate voltage, and $V_{\mathrm{T}}$ 
is the threshold voltage.

4. UV-vis absorption spectra of polymer solutions.
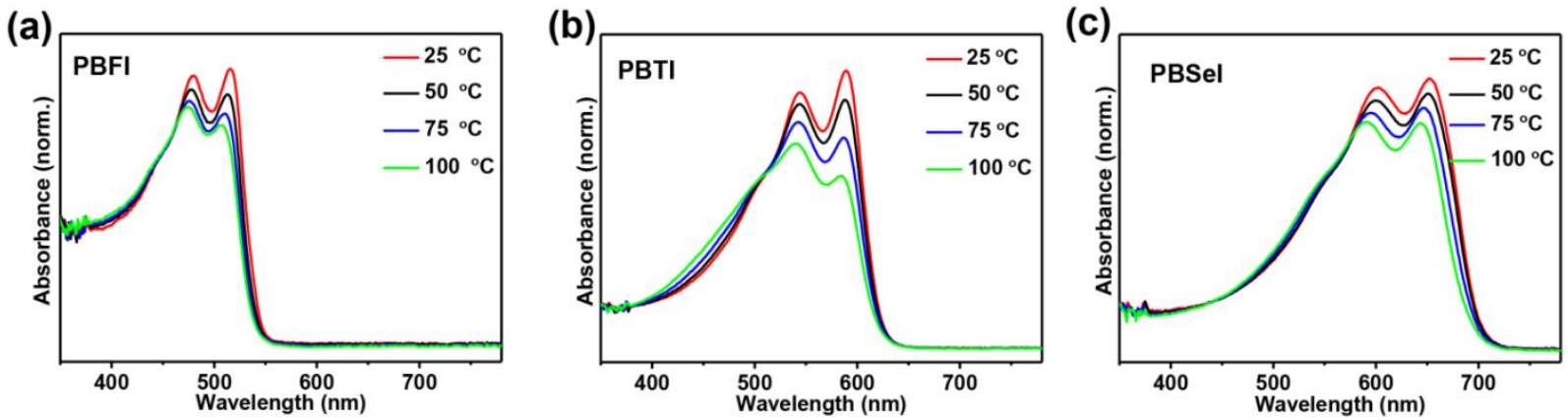

Figure S1. UV-vis absorption spectra of polymers (a) PBFI, (b) PBTI, and (c) PBSeI in diluted $o$-DCB solution $\left(1 \times 10^{-5} \mathrm{M}\right)$ at various temperatures as indicated.

(a)

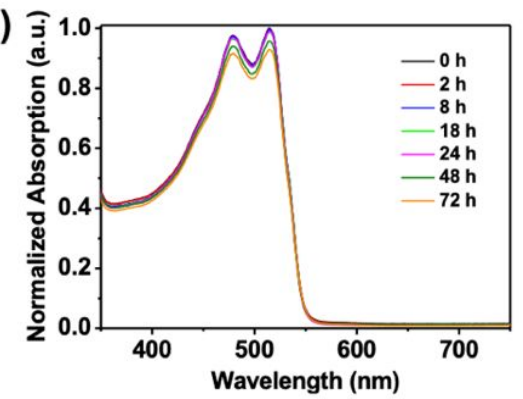

(b)

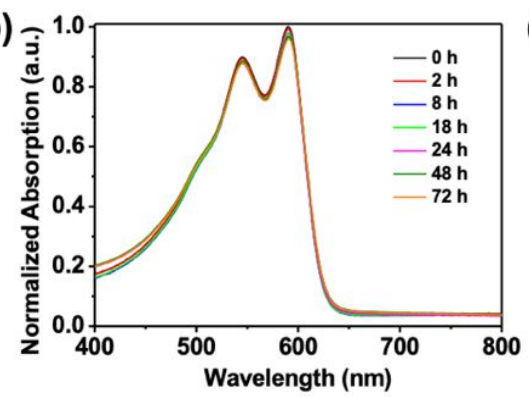

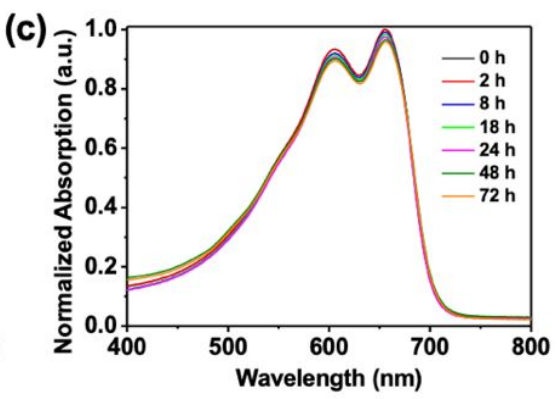

Figure S2. UV-Vis absorption spectra of polymers (a) PBFI, (b) PBTI, and (c) PBSeI $\left(1 \times 10^{-5} \mathrm{M}\right.$ in $o$-dichlorobenzene) as a function of time under ambient light.

\section{Thermal properties of monomers and polymers.}

(a)

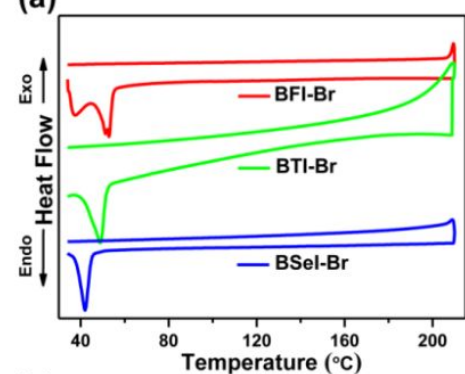

(c)

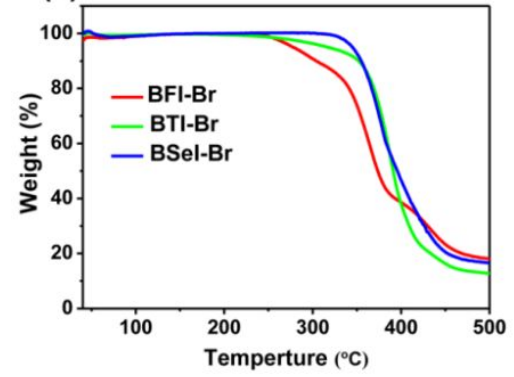

(b)

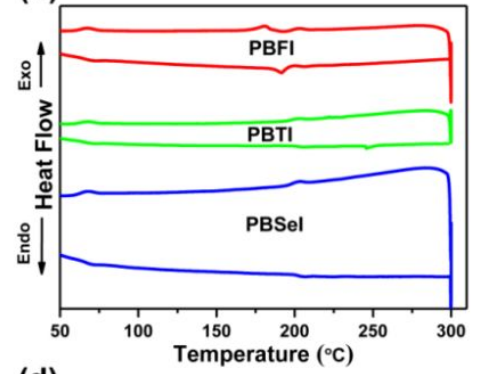

(d)

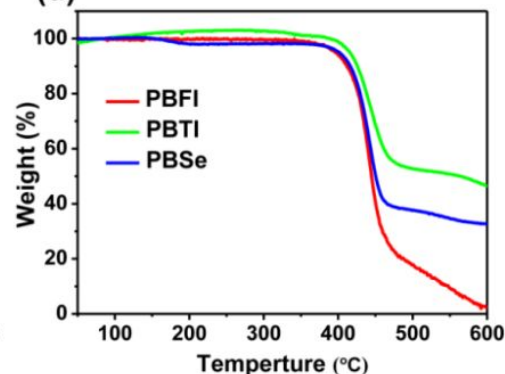

Figure S3. DSC thermograms of (a) dibrominated monomers and (b) homopolymers at a temperature ramp of $10{ }^{\circ} \mathrm{C} \mathrm{min}-1$ under $\mathrm{N}_{2}$. The top line is from the cooling run and the bottom line is from the heating run. Thermogravimetric analysis (heating ramp: $10{ }^{\circ} \mathrm{C} \mathrm{min}{ }^{-1}$ ) of (c) dibrominated 
monomers and (d) polymers. $\mathrm{N}_{2}$ was used as the purge gas for the TGA measurement.

6. DFT computation.

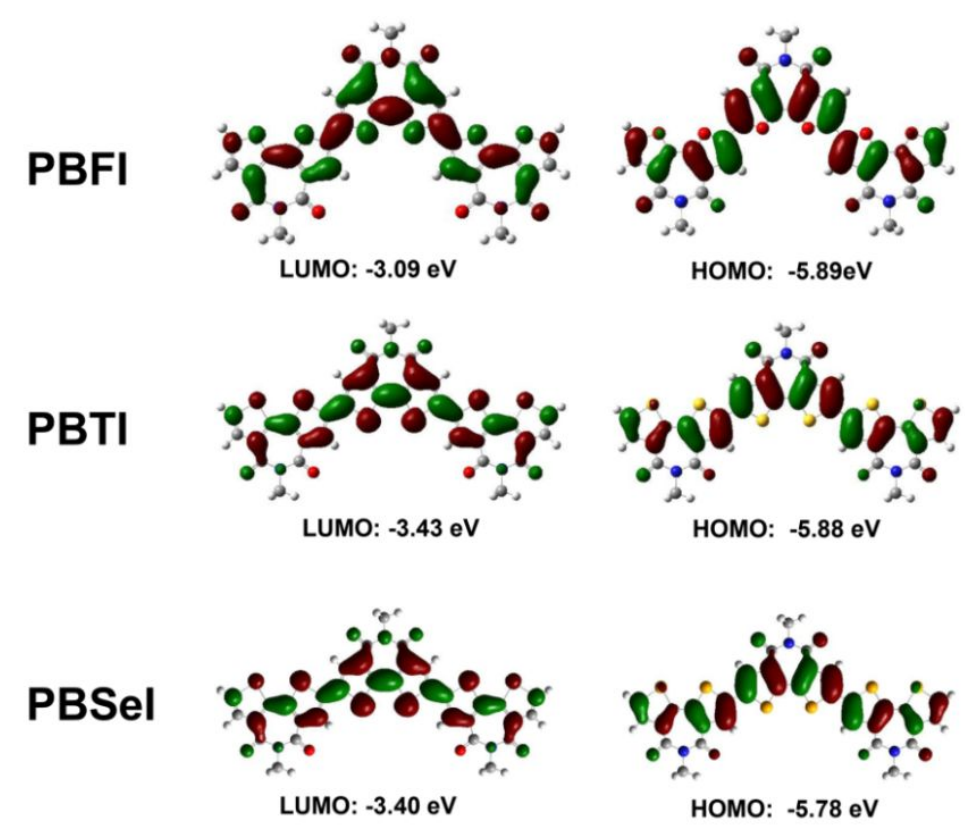

Figure S4. FMO energy levels of the trimers of polymer repeating units based on DFT calculation.

\section{OTFT performance of polymers.}

Table S1. Device performance parameters of PBFI, PBTI, and PBSeI-based OTFTs annealed at different temperature.

\begin{tabular}{|c|c|c|c|c|c|}
\hline Polymer & Solvent & $\begin{array}{c}T_{\text {annealing }} \\
\left({ }^{\circ} \mathrm{C}\right)\end{array}$ & $\begin{array}{c}\mu_{\mathrm{e}} \\
{\left[\mathrm{cm}^{2} \mathrm{~V}^{-1} \mathrm{~s}^{-1}\right]^{\mathrm{a}}}\end{array}$ & $\begin{array}{l}V_{T, \text { avg }} \\
{[\mathrm{V}]^{\mathrm{b}}}\end{array}$ & $I_{\mathrm{on}} / I_{\mathrm{off}}$ \\
\hline \multirow{7}{*}{ PBFI } & \multirow[t]{3}{*}{$\mathrm{CB}$} & 100 & $0.0097(0.0057)$ & 36 & $10^{6}$ \\
\hline & & 150 & $0.0061(0.0037)$ & 36 & $10^{5}$ \\
\hline & & 200 & $0.036(0.026)$ & 49 & $10^{6}$ \\
\hline & \multirow[t]{4}{*}{$o$-DCB } & As cast & $0.085(0.053)$ & 56 & $10^{4}$ \\
\hline & & 100 & $0.042(0.034)$ & 55 & $10^{4}$ \\
\hline & & 150 & $0.020(0.013)$ & 50 & $10^{3}$ \\
\hline & & 200 & $0.014(0.0081)$ & 56 & $10^{3}$ \\
\hline \multirow{7}{*}{ PBTI } & \multirow[t]{3}{*}{$\mathrm{CB}^{\mathrm{c}}$} & 120 & $1.53(1.09)$ & 32 & $10^{6}$ \\
\hline & & 160 & $1.53(1.19)$ & 25 & $10^{6}$ \\
\hline & & 200 & $1.18(0.97)$ & 23 & $10^{6}$ \\
\hline & \multirow[t]{4}{*}{$o-\mathrm{DCB}$} & As cast & $0.41(0.31)$ & 38 & $10^{6}$ \\
\hline & & 100 & $0.28(0.23)$ & 39 & $10^{6}$ \\
\hline & & 150 & $0.40(0.35)$ & 42 & $10^{6}$ \\
\hline & & 200 & $0.36(0.29)$ & 41 & $10^{6}$ \\
\hline \multirow{3}{*}{ PBSeI } & \multirow[t]{3}{*}{$\mathrm{CB}$} & As cast & $0.41(0.31)$ & 38 & $10^{5}$ \\
\hline & & 100 & $0.28(0.23)$ & 39 & $10^{5}$ \\
\hline & & 150 & $0.40(0.35)$ & 42 & $10^{5}$ \\
\hline
\end{tabular}




\begin{tabular}{ccccc}
\hline & 200 & $0.36(0.29)$ & 41 & $10^{4}$ \\
\hline \multirow{2}{*}{$o$-DCB } & As cast & $0.43(0.29)$ & 30 & $10^{6}$ \\
& 100 & $0.74(0.42)$ & 28 & $10^{6}$ \\
& 150 & $0.82(0.49)$ & 32 & $10^{6}$ \\
& 200 & $0.47(0.44)$ & 40 & $10^{5}$ \\
\hline
\end{tabular}

${ }^{\text {a }}$ Data represent the best mobility in OTFT devices with the average mobility from at least 5 OTFT devices shown in parentheses. ${ }^{\mathrm{b}}$ Average threshold voltages. ${ }^{\mathrm{c}}$ Data taken from literature ${ }^{3}$.

Table S2. Device performance parameters of homopolymer PBSeI* and PBSeI having distinct molecular weight. The PBSeI* and PBSeI-based OTFTs using $o$-DCB as the processing solvent and thermally annealed at 150 and $200^{\circ} \mathrm{C}$.

\begin{tabular}{lccrrr} 
Polymer & $\mathrm{M}_{\mathrm{n}}[\mathrm{kDa}]$ & $T_{\text {annealing }}\left({ }^{\circ} \mathrm{C}\right)$ & $\begin{array}{c}\mu_{\mathrm{e}} \\
{\left[\mathrm{cm}^{2} \mathrm{~V}^{-1} \mathrm{~s}^{-1}\right]^{\mathrm{a}}}\end{array}$ & $V_{T, \text { avg }}[\mathrm{V}]^{\mathrm{b}}$ & $I_{\text {on }} / I_{\text {off }}$ \\
\hline PBSeI* & 8.2 & 150 & $0.52(0.35)$ & 26 & $10^{7}$ \\
& & 200 & $0.45(0.29)$ & 30 & $10^{7}$ \\
\hline PBSeI & 16.5 & 150 & $0.82(0.49)$ & 32 & $10^{6}$ \\
& & 200 & $0.47(0.44)$ & 40 & $10^{5}$ \\
\hline
\end{tabular}

a Data represent the best mobility in OTFT devices with the average mobility from at least 5 OTFT devices shown in parentheses. ${ }^{\mathrm{b}}$ Average threshold voltages. 
8. 2D-GIWAX data of polymer films.

Table S3. Packing parameters derived from 2D-GIWAX measurements.

\begin{tabular}{|c|c|c|c|c|}
\hline Polymer & \multicolumn{2}{|c|}{ Crystallographic parameters } & As cast & Annealed \\
\hline \multirow{6}{*}{ PBFI } & \multirow{3}{*}{$\begin{array}{c}\mathrm{q}_{\mathrm{z}} \\
\text { profile } \\
(100)\end{array}$} & $q\left(\AA^{-1}\right)$ & 0.25 & 0.25 \\
\hline & & CCL (nm) & 12.48 & 11.27 \\
\hline & & d-spacing $(\AA)$ & 25.12 & 25.12 \\
\hline & \multirow{3}{*}{$\begin{array}{c}\mathrm{q}_{\mathrm{xy}} \\
\text { profile } \\
(100)\end{array}$} & $q\left(\AA^{-1}\right)$ & 0.24 & 0.25 \\
\hline & & CCL (nm) & 14.25 & 12.83 \\
\hline & & d-spacing $(\AA)$ & 26.17 & 26.17 \\
\hline \multirow{10}{*}{ PBTI } & \multirow{3}{*}{$\begin{array}{c}\mathrm{q}_{\mathrm{z}} \\
\text { profile } \\
(100)\end{array}$} & $q\left(\AA^{-1}\right)$ & 0.20 & 0.20 \\
\hline & & CCL (nm) & 9.4 & 9.3 \\
\hline & & d-spacing $(\AA)$ & 31.4 & 31.4 \\
\hline & \multirow{3}{*}{$\begin{array}{c}\mathrm{q}_{\mathrm{xy}} \\
\text { profile } \\
(100)\end{array}$} & $q\left(\AA^{-1}\right)$ & 0.25 & 0.25 \\
\hline & & CCL (nm) & 30.70 & 30.80 \\
\hline & & d-spacing $(\AA)$ & 25.6 & 25.6 \\
\hline & \multirow{2}{*}{$\begin{array}{c}\mathrm{q}_{\mathrm{z}} \\
\text { profile } \\
(010)\end{array}$} & $\mathrm{q}\left(\AA^{-1}\right)$ & 1.72 & 1.72 \\
\hline & & d-spacing $(\AA)$ & 3.70 & 3.70 \\
\hline & \multirow{2}{*}{$\begin{array}{c}\mathrm{q}_{\mathrm{xy}} \\
\text { profile } \\
(010)\end{array}$} & $q\left(\AA^{-1}\right)$ & 1.71 & 1.71 \\
\hline & & d-spacing $(\AA)$ & 3.69 & 3.69 \\
\hline \multirow[t]{10}{*}{ PBSeI } & \multirow{3}{*}{$\begin{array}{c}\mathrm{q}_{\mathrm{z}} \\
\text { profile } \\
(100)\end{array}$} & $q\left(\AA^{-1}\right)$ & 0.25 & 0.25 \\
\hline & & CCL (nm) & 9.83 & 11.11 \\
\hline & & d-spacing $(\AA)$ & 25.12 & 25.12 \\
\hline & \multirow{3}{*}{$\begin{array}{c}\mathrm{q}_{\mathrm{xy}} \\
\text { profile } \\
(100)\end{array}$} & $q\left(\AA^{-1}\right)$ & 0.24 & 0.24 \\
\hline & & CCL (nm) & 10.89 & 13.67 \\
\hline & & d-spacing $(\AA)$ & 26.17 & 26.17 \\
\hline & \multirow{2}{*}{$\begin{array}{c}\mathrm{q}_{\mathrm{z}} \\
\text { profile } \\
(010)\end{array}$} & $q\left(\AA^{-1}\right)$ & 1.67 & 1.68 \\
\hline & & d-spacing $(\AA)$ & 3.76 & 3.74 \\
\hline & \multirow{2}{*}{$\begin{array}{c}\mathrm{q}_{\mathrm{xy}} \\
\text { profile } \\
(010)\end{array}$} & $q\left(\AA^{-1}\right)$ & 1.67 & 1.67 \\
\hline & & d-spacing $(\AA)$ & 3.76 & 3.76 \\
\hline
\end{tabular}


-As Cast
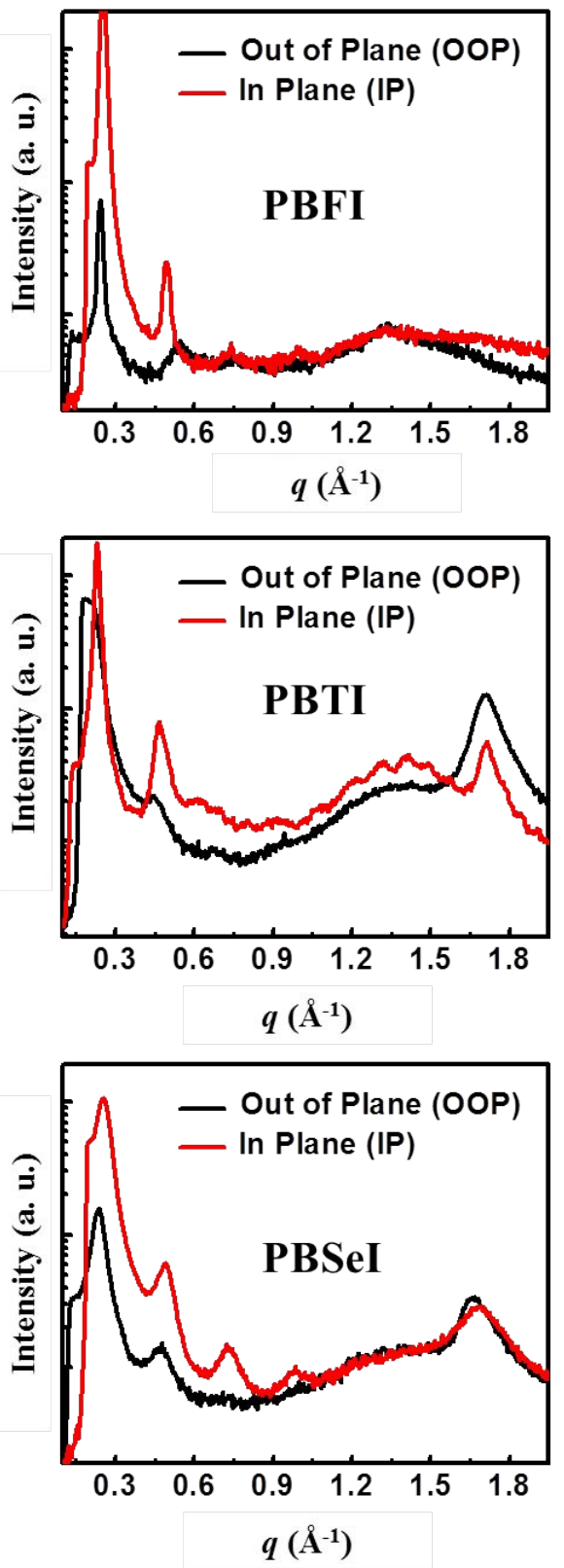

-Annealed
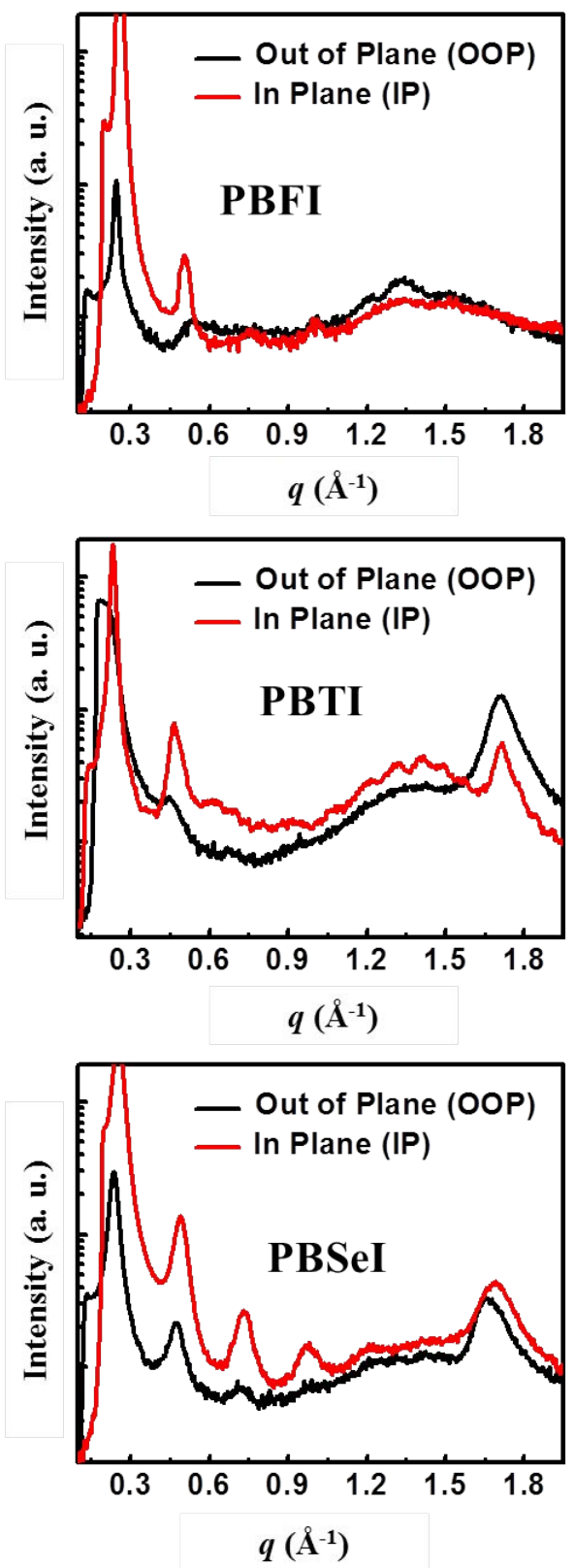

Figure S5. In-plane (IP) and out-of-plane (OOP) line-cut profiles of 2D-GIWAXS measurements of polymer films. 
8. NMR and HRMS spectra.

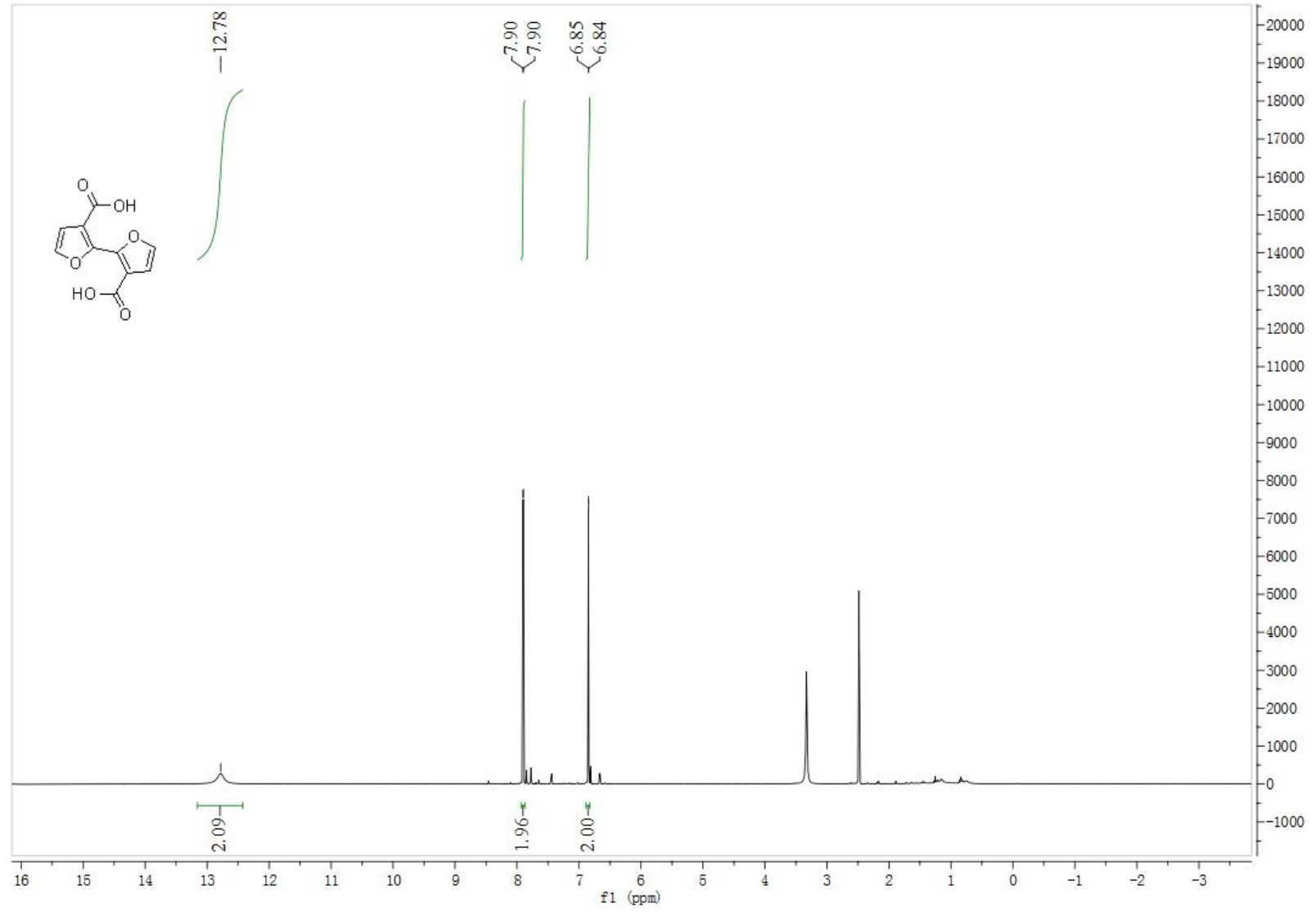

Figure S6. ${ }^{1} \mathrm{H}$ NMR spectrum of compound 2 (r.t., in DMSO- $d_{6}$ ).

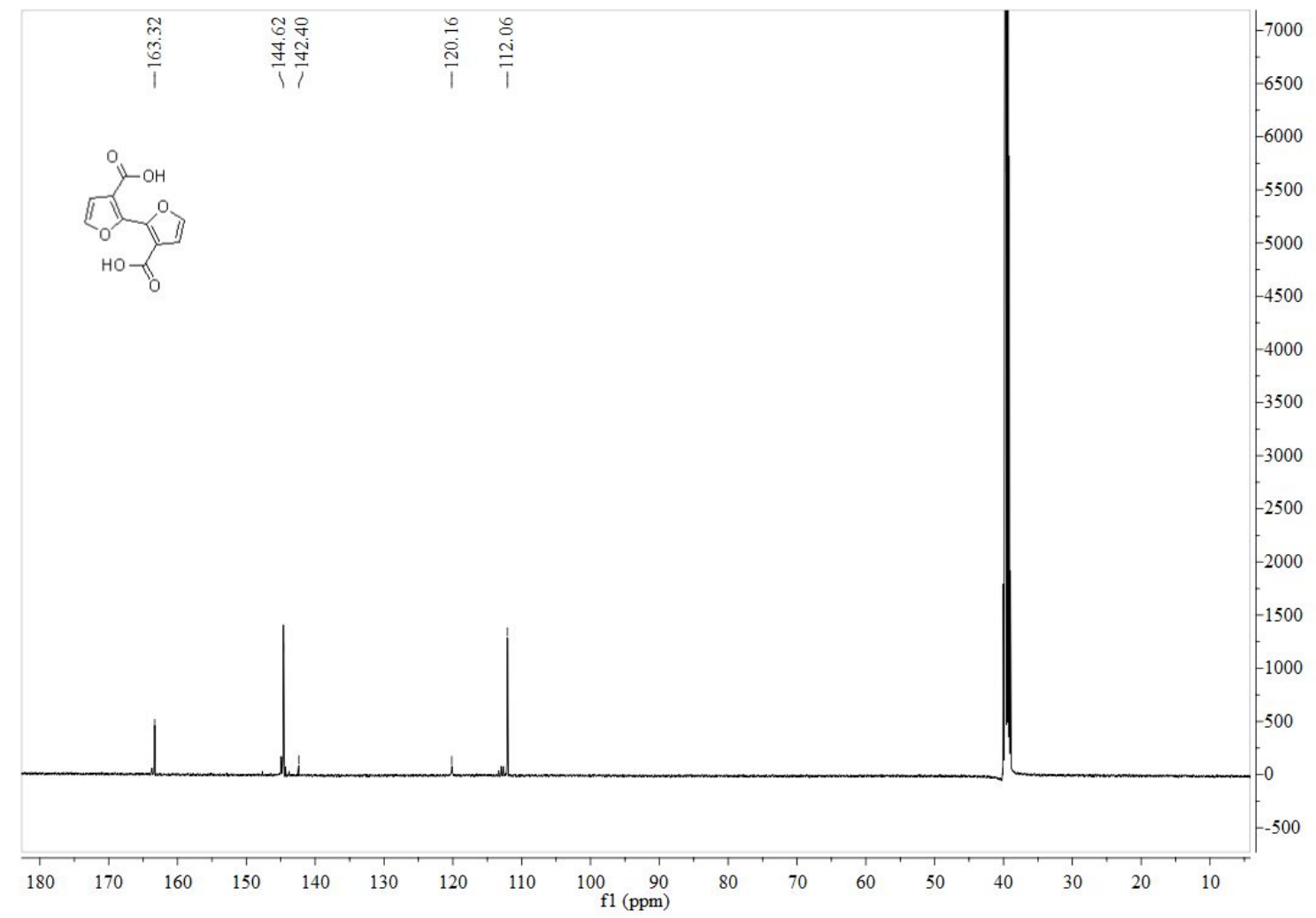

Figure S7. ${ }^{13} \mathrm{C}$ NMR spectrum of compound 2 (r.t., in DMSO- $d_{6}$ ). 
Zoom in $[\mathrm{M}+\mathrm{H}]$

F-COOH_170919132910 \#33 RT: 0.32 AV: 1 NL: $1.72 E 7$ T: FTMS + p ESI Full ms [100.0000-600.0000]

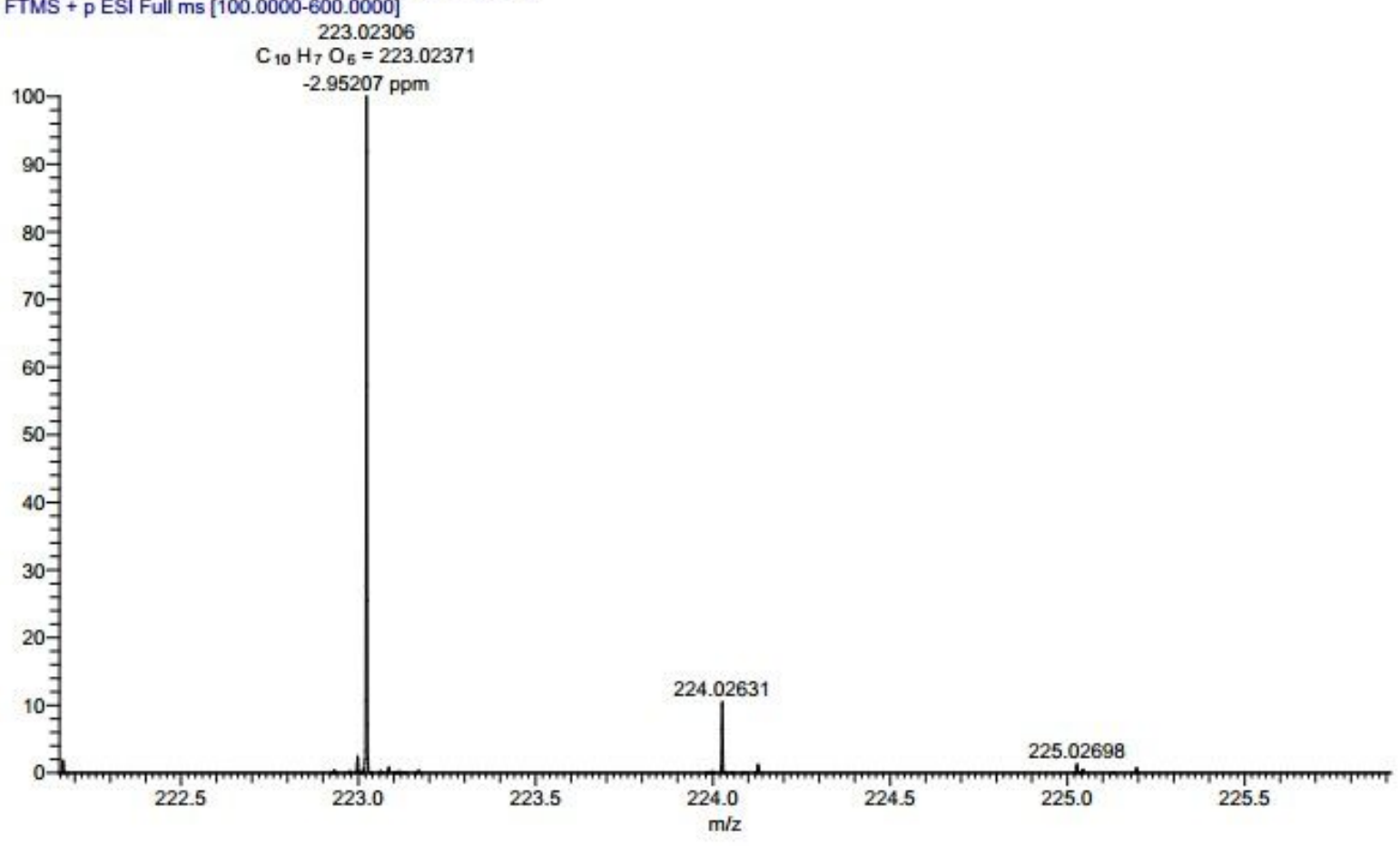

Figure S8. HRMS spectrum of compound 2.

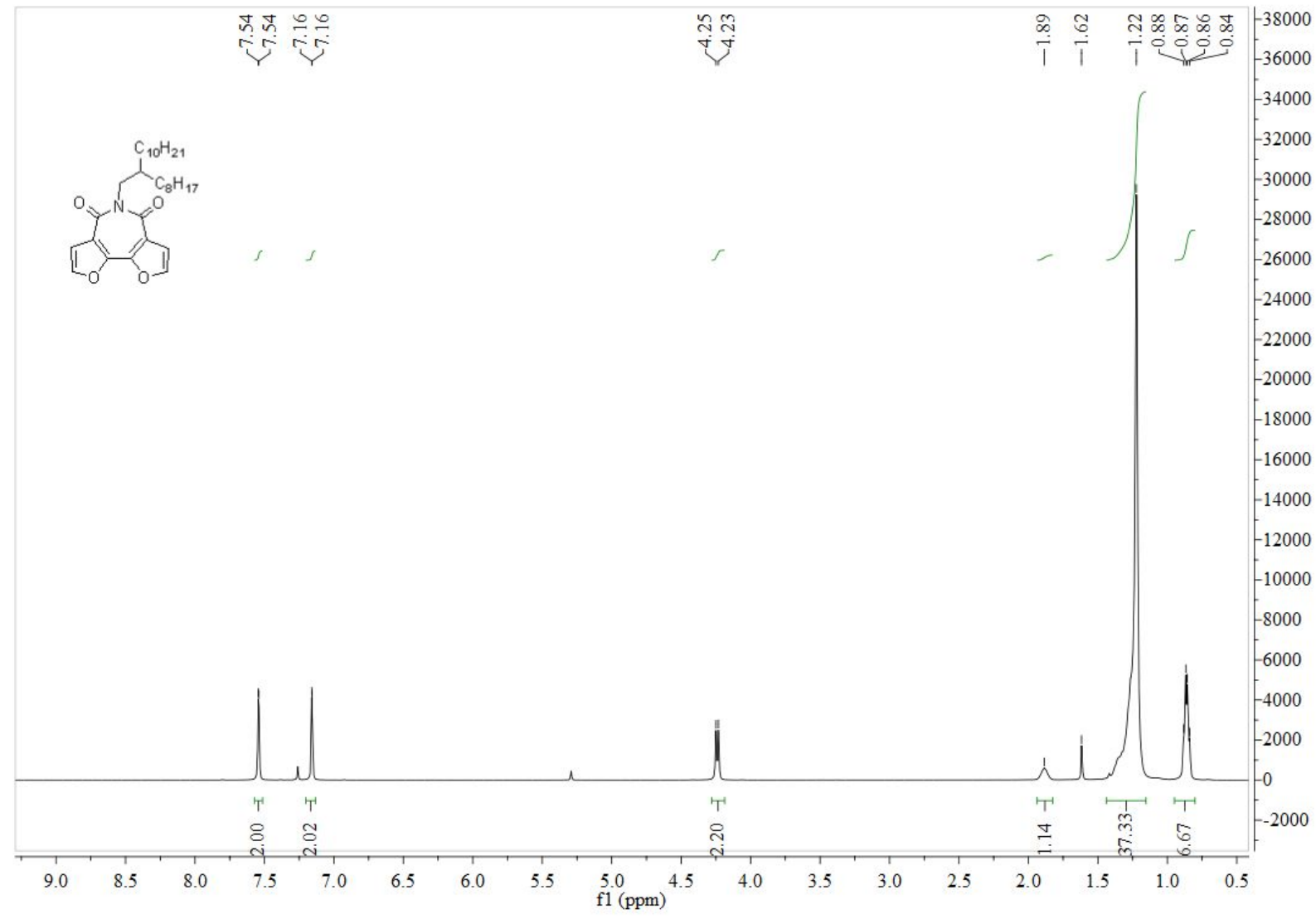

Figure S9. ${ }^{1} \mathrm{H}$ NMR spectrum of compound BFI (r.t., in $\mathrm{CDCl}_{3}$ ). 


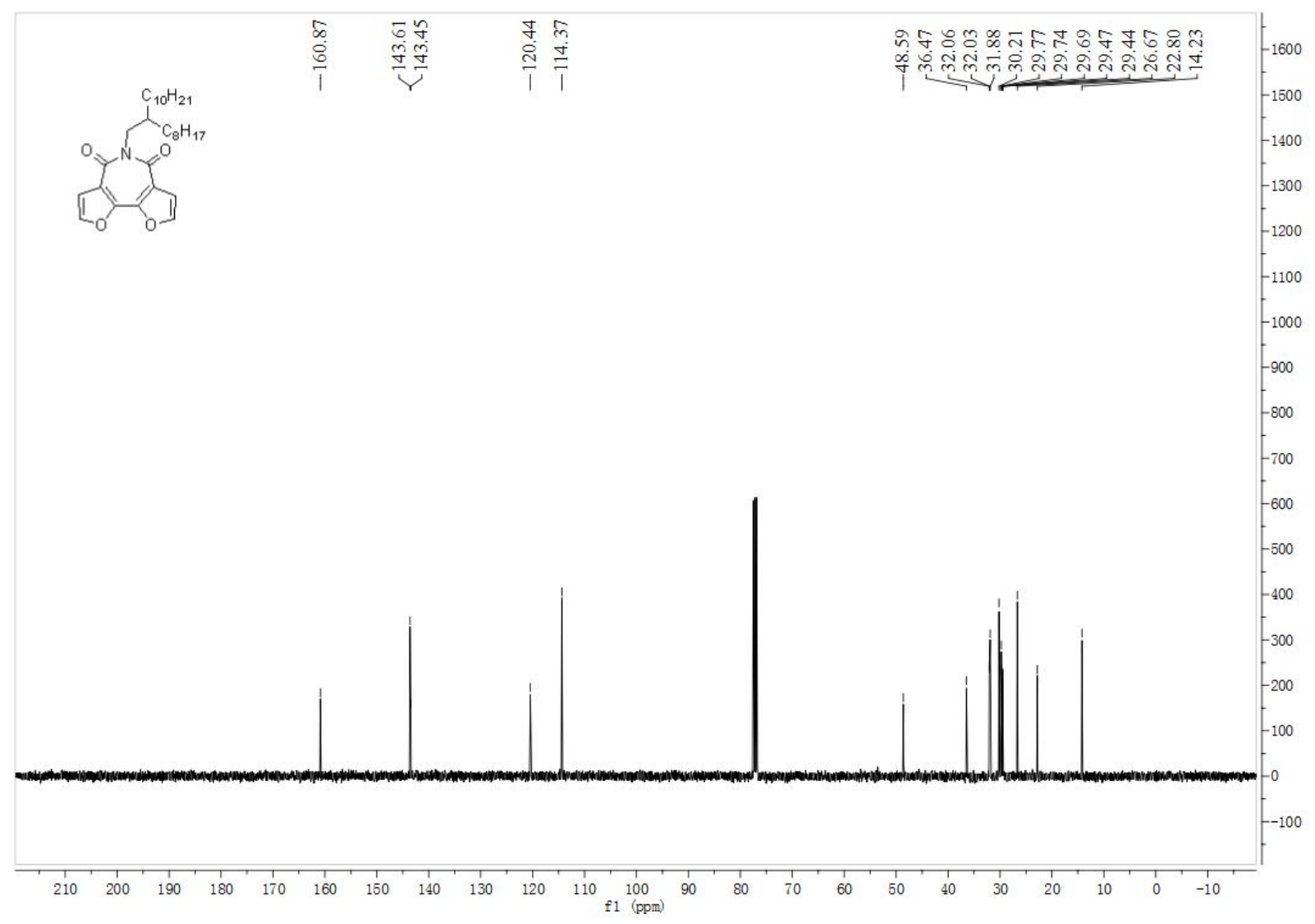

Figure S10. ${ }^{13} \mathrm{C}$ NMR spectrum of compound BFI (r.t., in $\mathrm{CDCl}_{3}$ ).

$[\mathrm{M}+\mathrm{H}]$

1 \#7 RT: 0.08 AV: 1 NL: $1.45 E 8$

T: FTMS + p ESI Full ms $[100.0000-800.0000]$

484.34134

$\mathrm{C}_{30} \mathrm{H}_{46} \mathrm{O}_{4} \mathrm{~N}=484.34214$

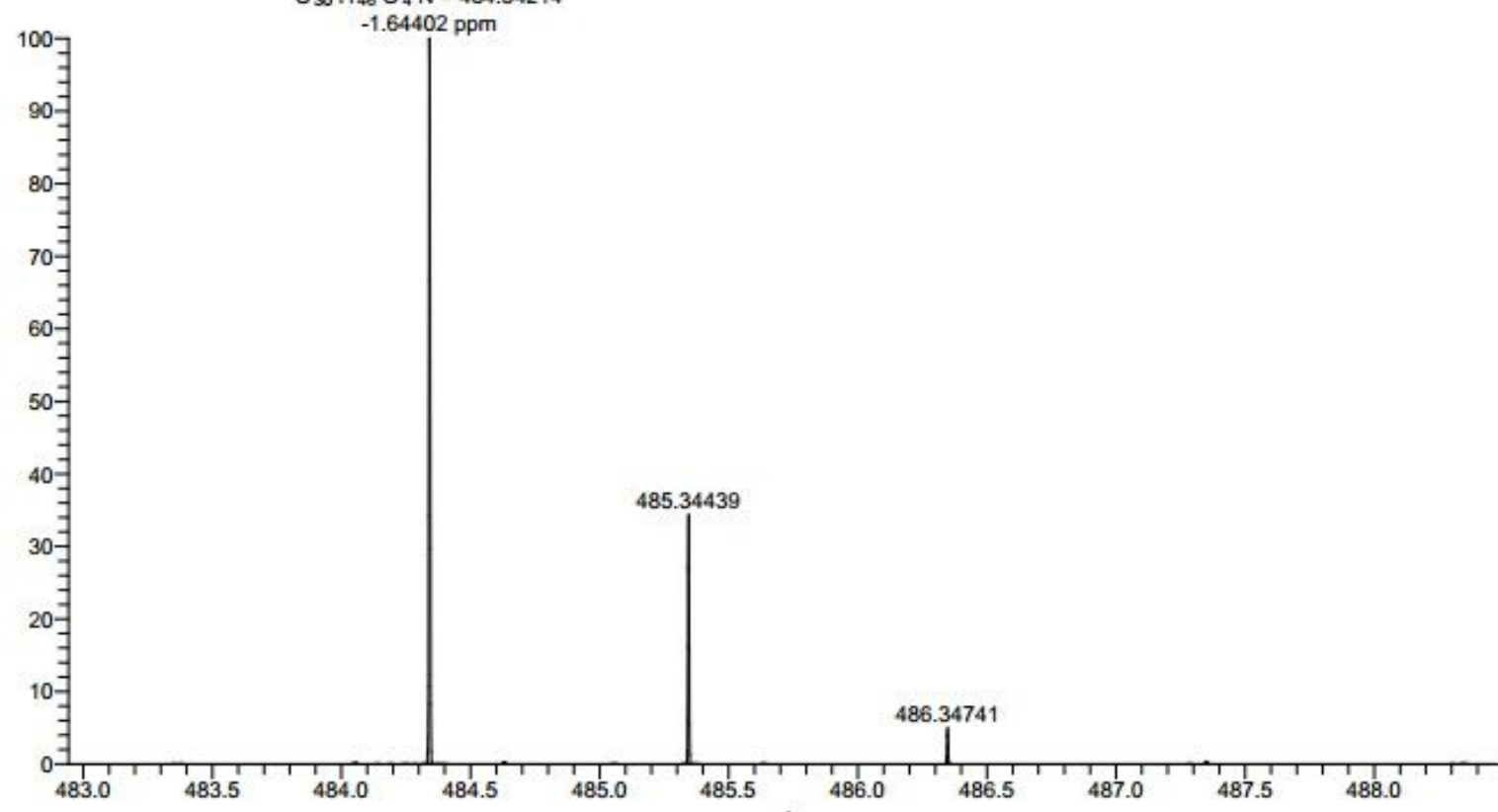

Figure S11. HRMS spectrum of compound BFI. 


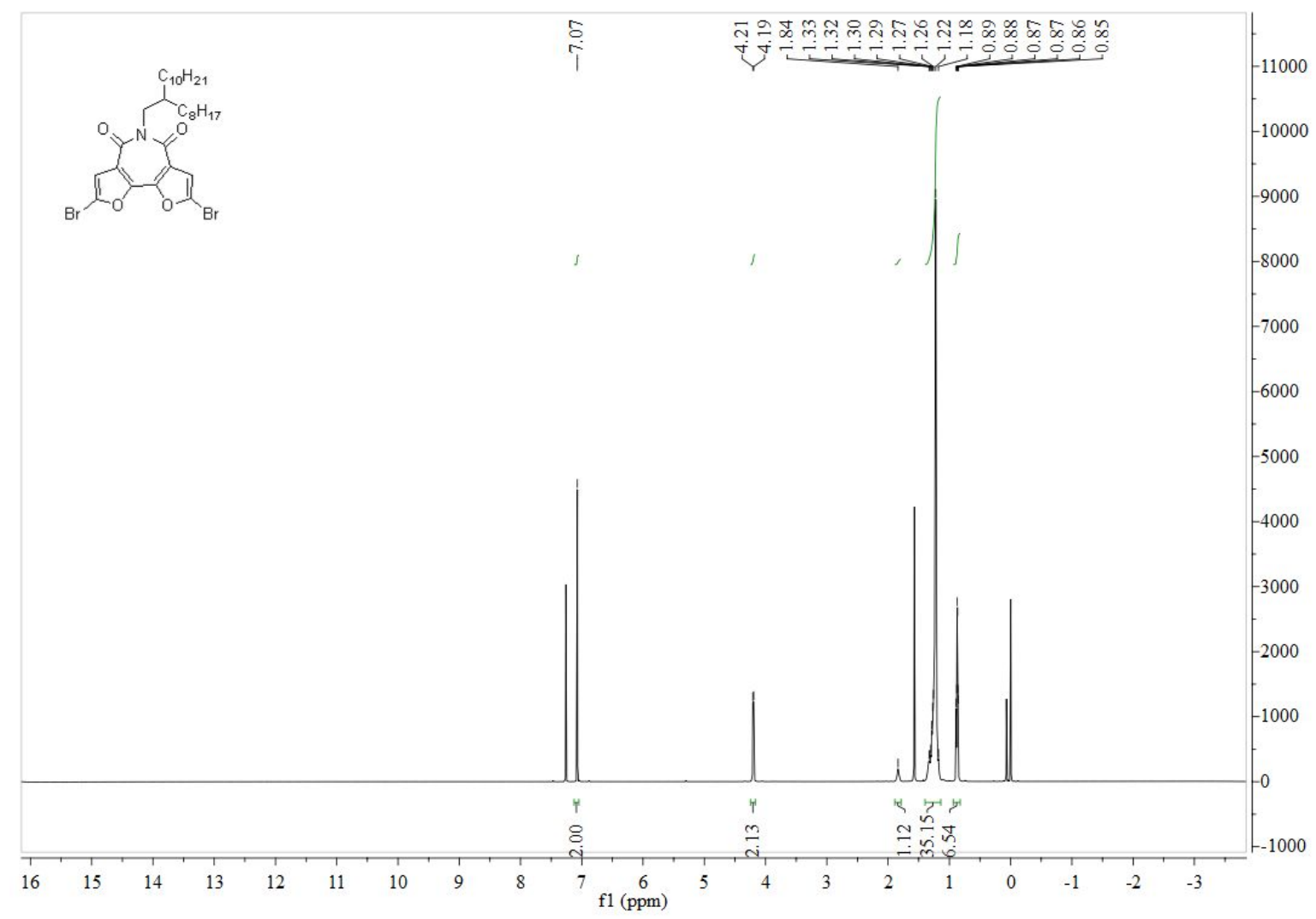

Figure S12. ${ }^{1} \mathrm{H}$ NMR spectrum of dibrominated monomer BFI-Br (r.t., in $\mathrm{CDCl}_{3}$ ).

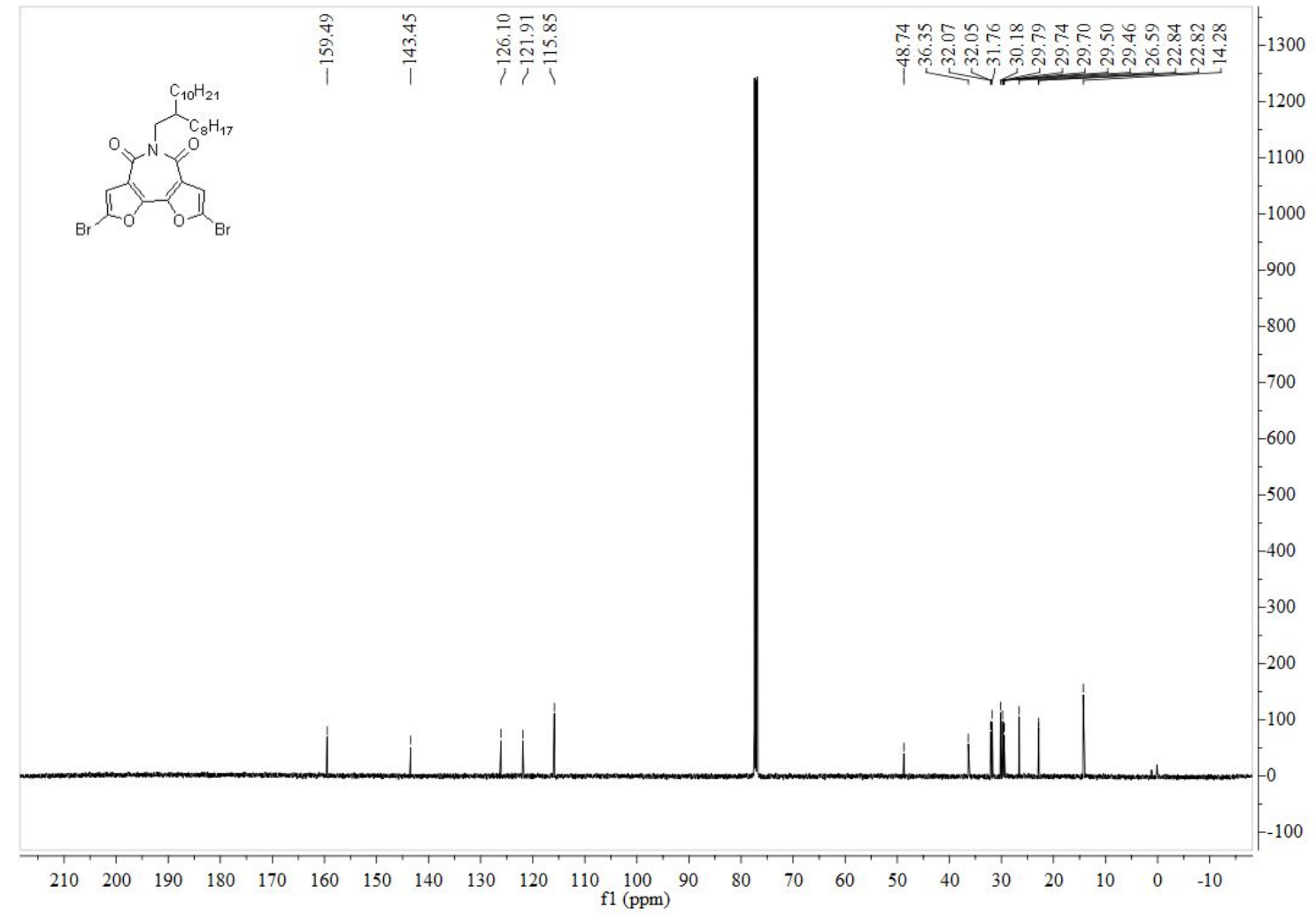

Figure S13. ${ }^{13} \mathrm{C}$ NMR spectrum of dibrominated monomer BFI-Br (r.t., in $\mathrm{CDCl}_{3}$ ). 
F-imide 170922153328 \#3 RT: 0.04 AV: 1 NL: $2.47 E 6$ T: FTMS + p ESI Full ms [100.0000-800.0000] 642.15881
$\mathrm{C}_{30} \mathrm{H}_{44} \mathrm{O}_{4} \mathrm{~N} \mathrm{Br}^{81} \mathrm{Br}=642.16111$

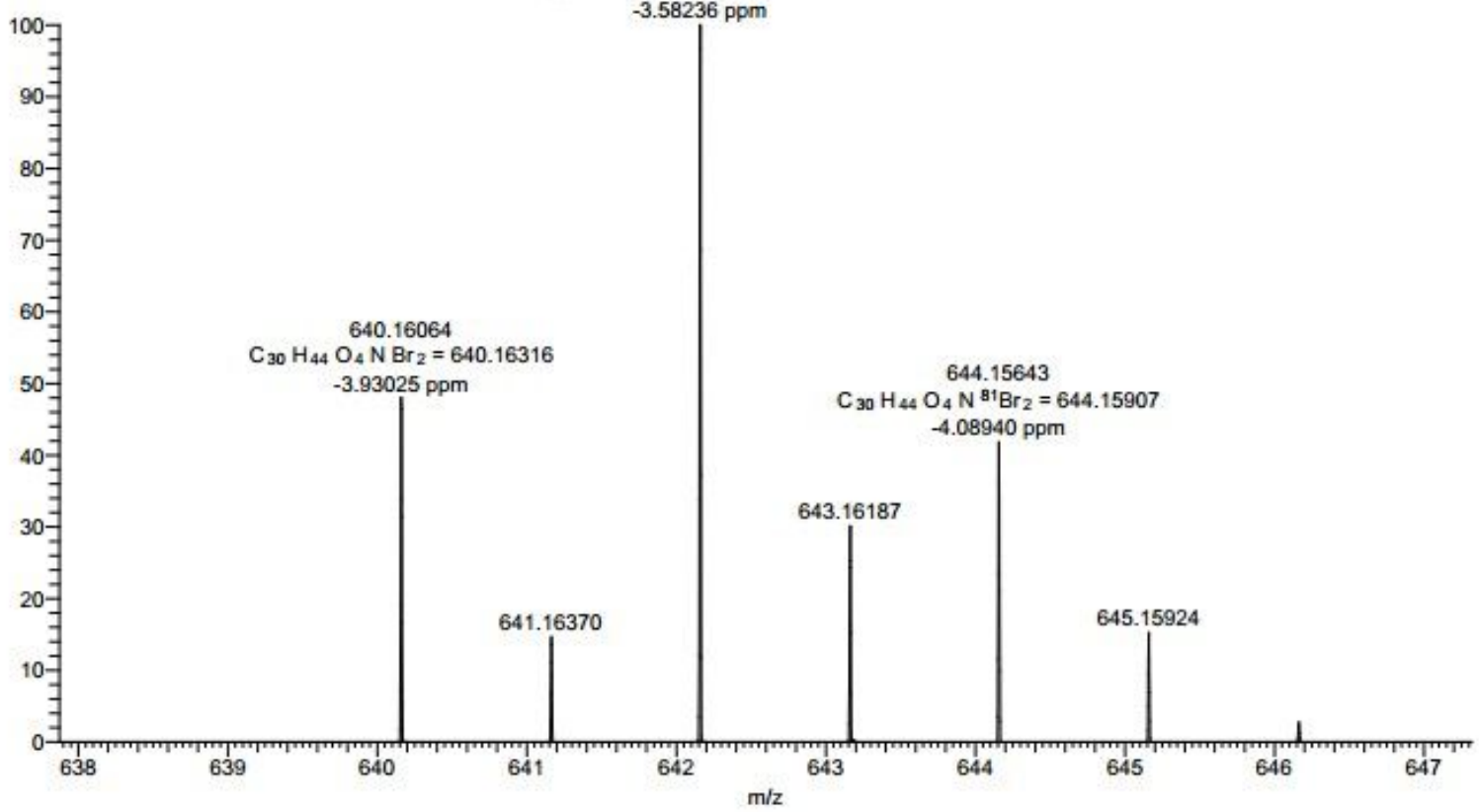

Figure S14. HRMS spectrum of dibrominated monomer BFI-Br.

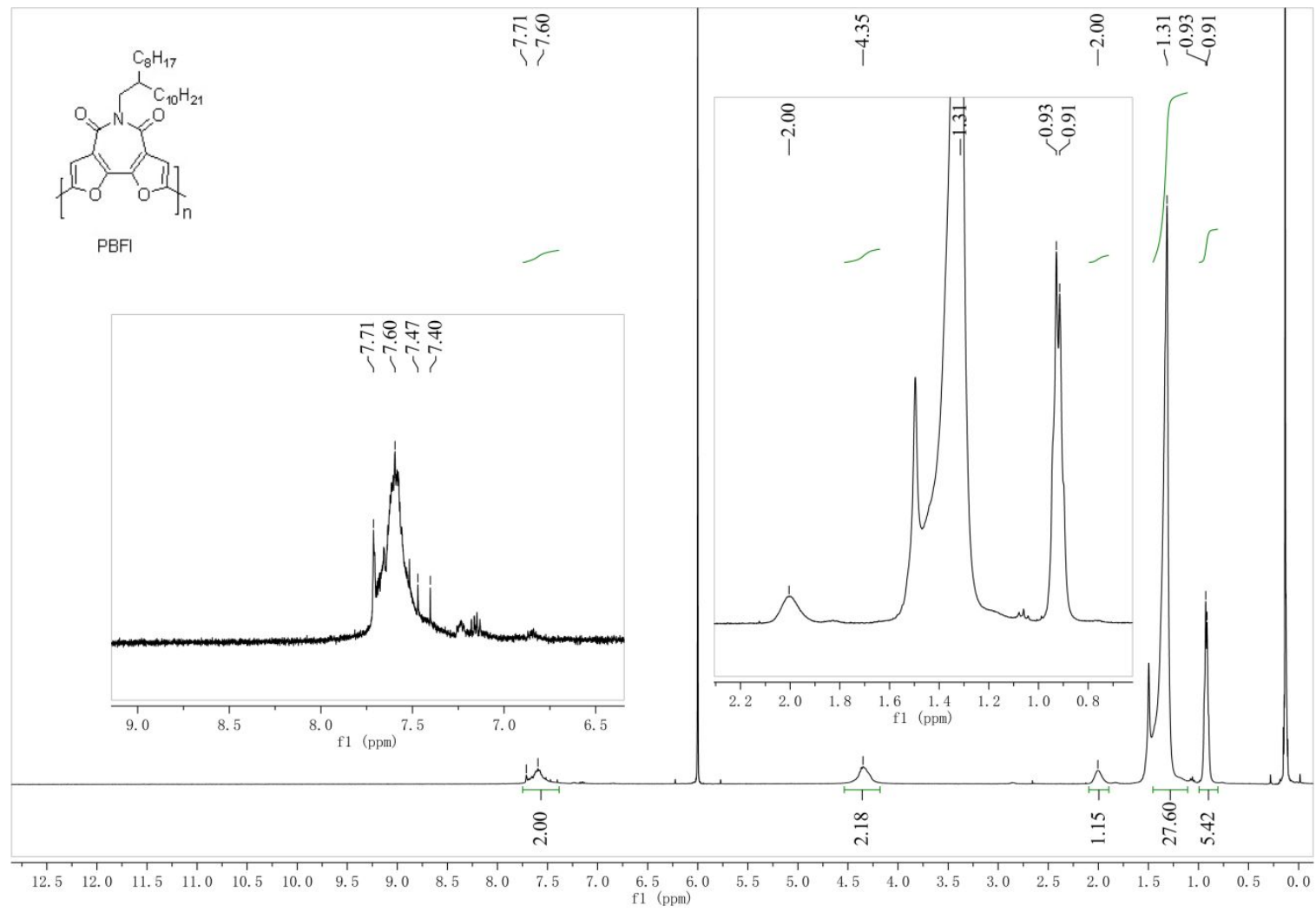

Figure S15. ${ }^{1} \mathrm{H}$ NMR spectrum of polymer PBFI $\left(80{ }^{\circ} \mathrm{C}\right.$ in $\left.\mathrm{C}_{2} \mathrm{D}_{2} \mathrm{Cl}_{4}\right)$. 


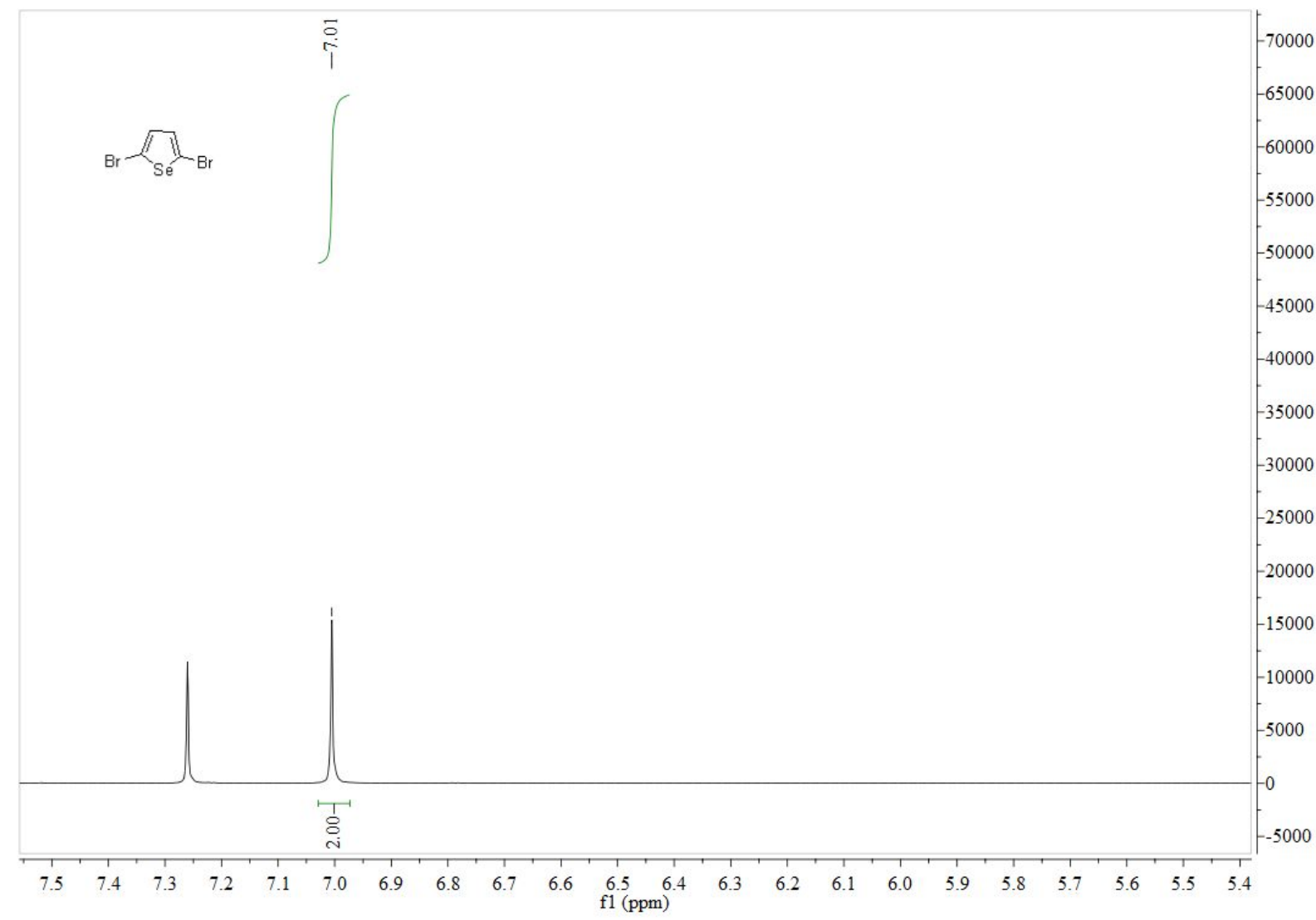

Figure S16. ${ }^{1} \mathrm{H}$ NMR spectrum of compound 5 (r.t., in $\mathrm{CDCl}_{3}$ ).

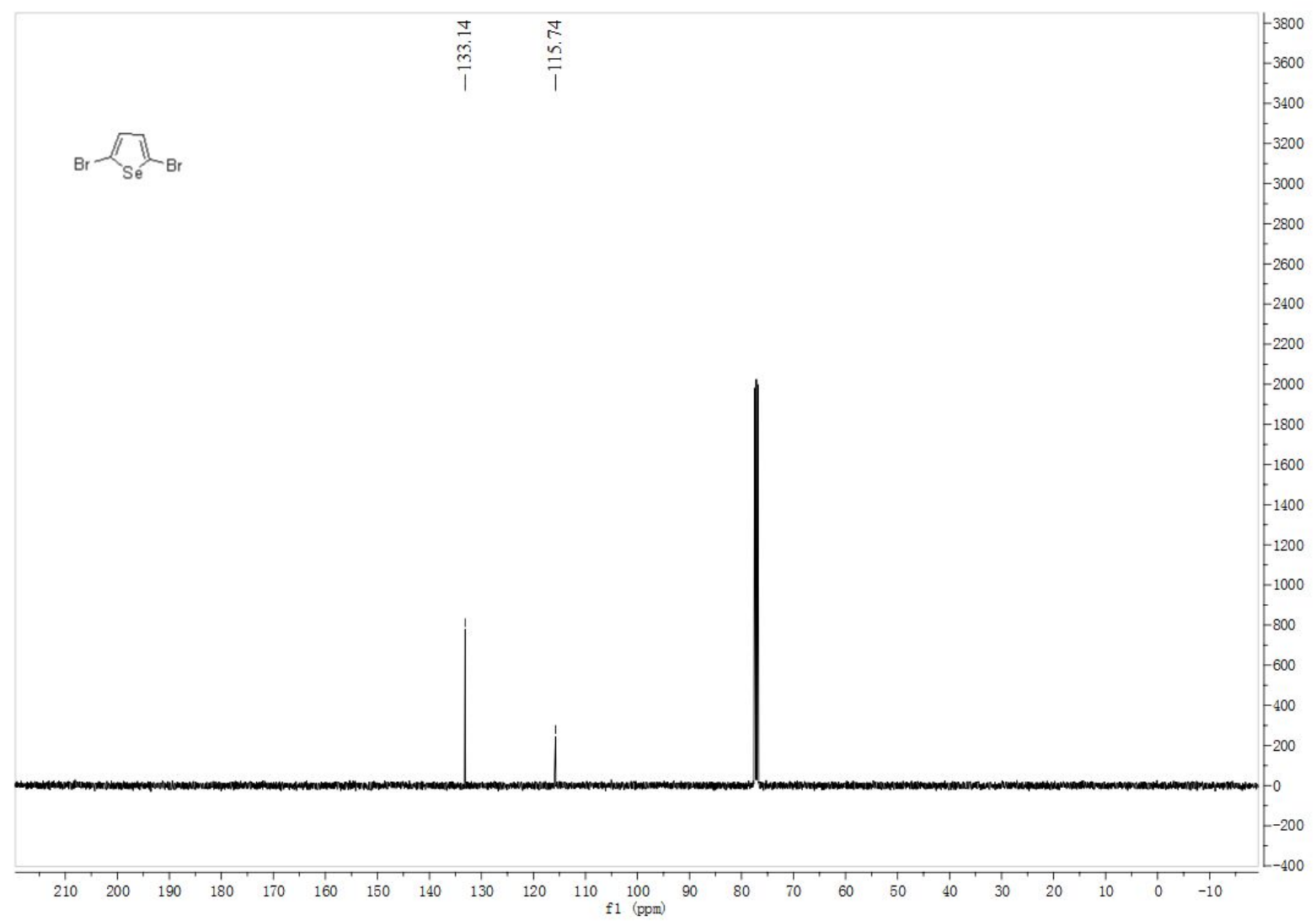

Figure S17. ${ }^{13} \mathrm{C}$ NMR spectrum of compound 5 (r.t., in $\mathrm{CDCl}_{3}$ ). 


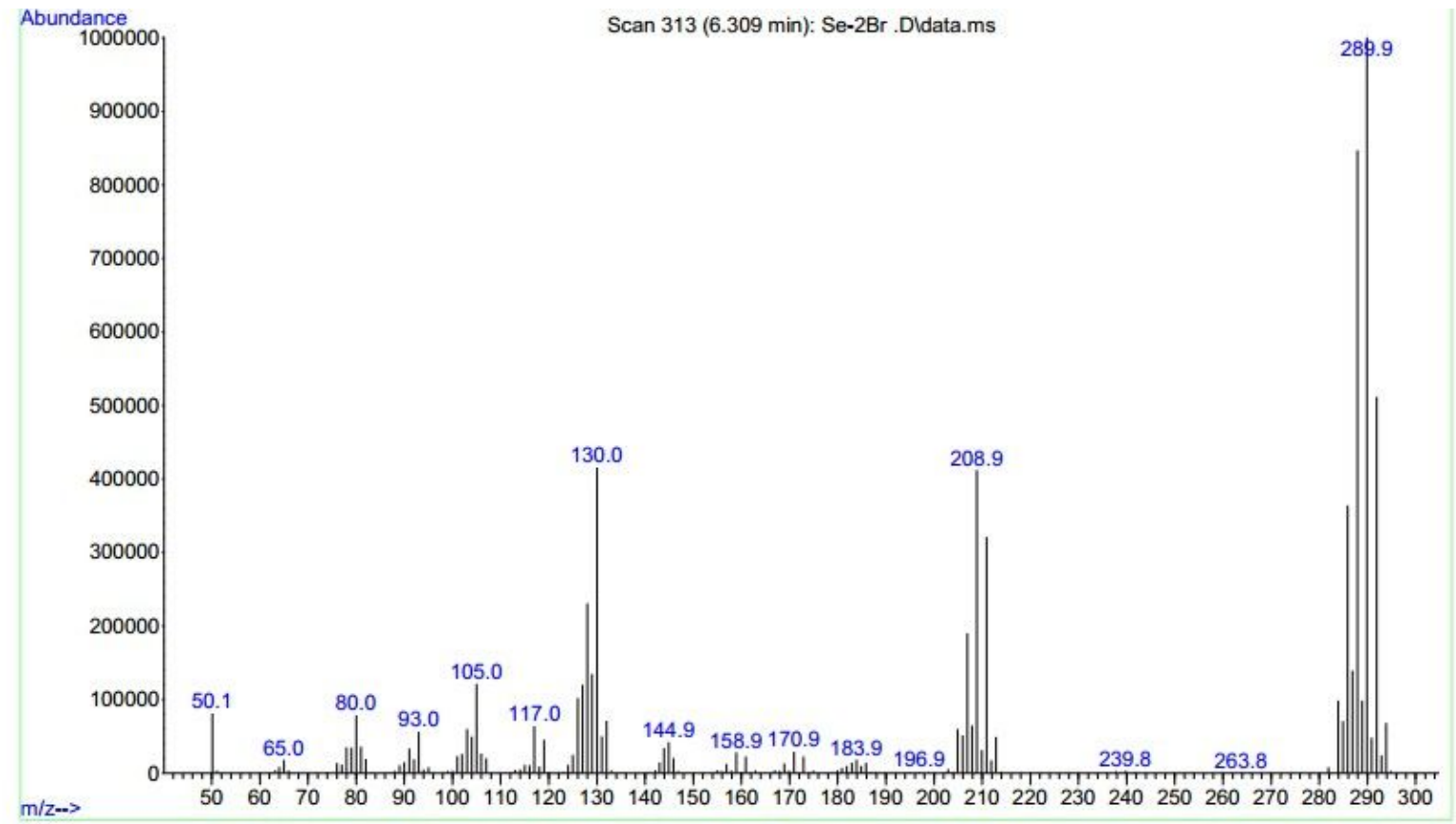

Figure S18. EI-MS spectrum of compound 5.

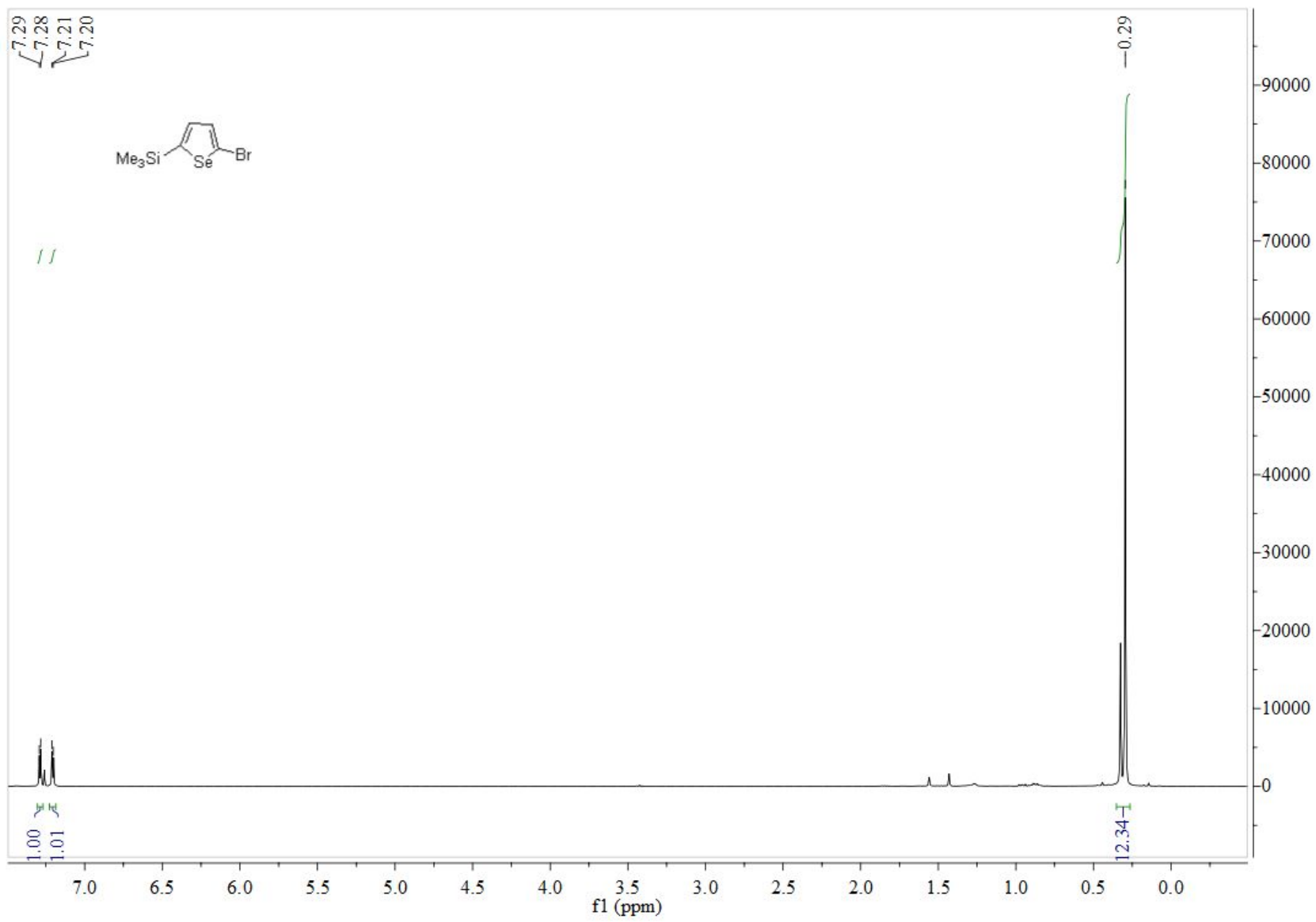

Figure S19. ${ }^{1} \mathrm{H}$ NMR spectrum of compound 6 (r.t., in $\mathrm{CDCl}_{3}$ ). 


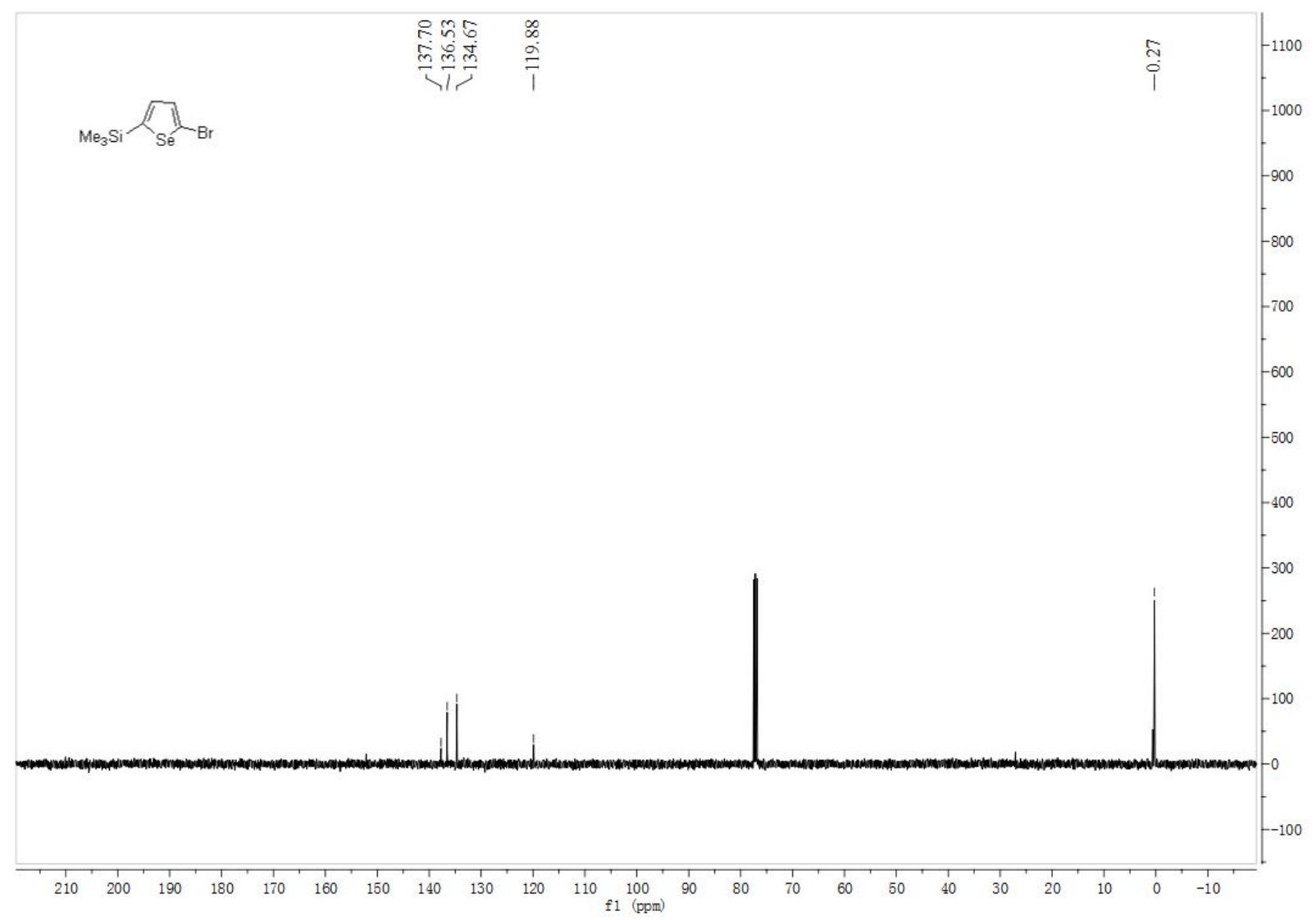

Figure S20. ${ }^{13} \mathrm{C}$ NMR spectrum of compound $\mathbf{6}$ (r.t., in $\mathrm{CDCl}_{3}$ ).

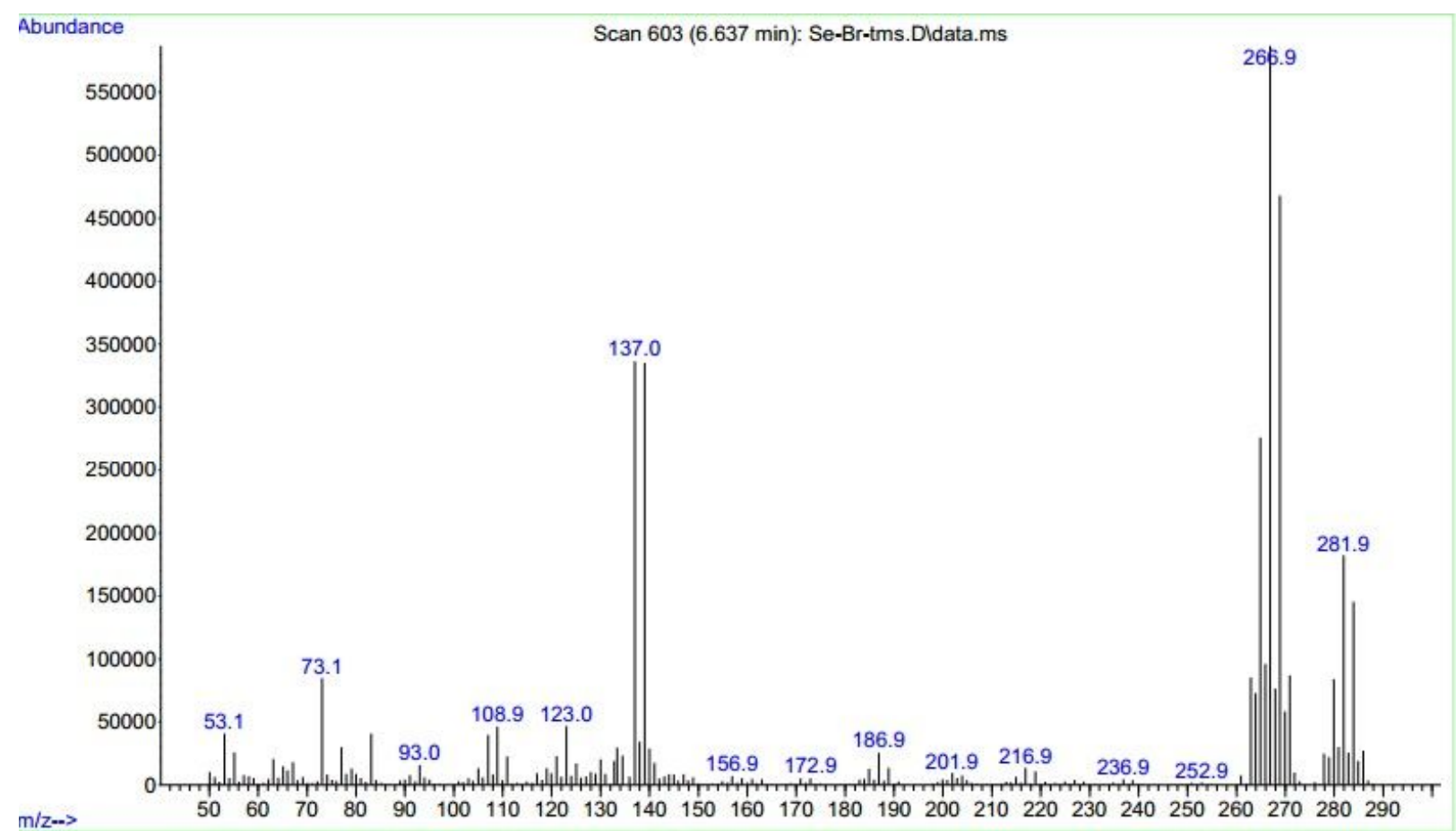

Figure S21. EI-MS spectrum of compound 6. 


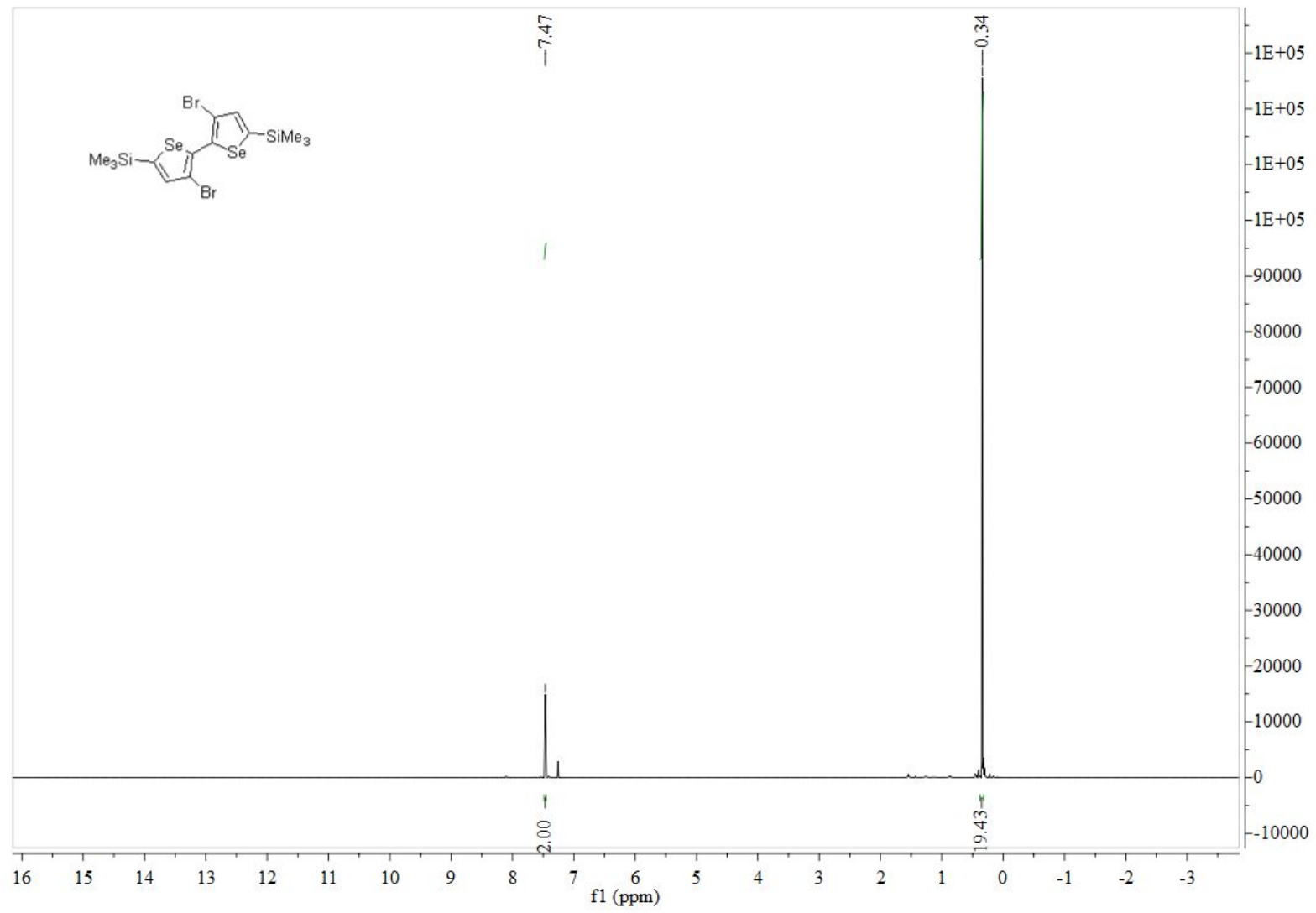

Figure S22. ${ }^{1} \mathrm{H}$ NMR spectrum of compound 7 (r.t., in $\mathrm{CDCl}_{3}$ ).

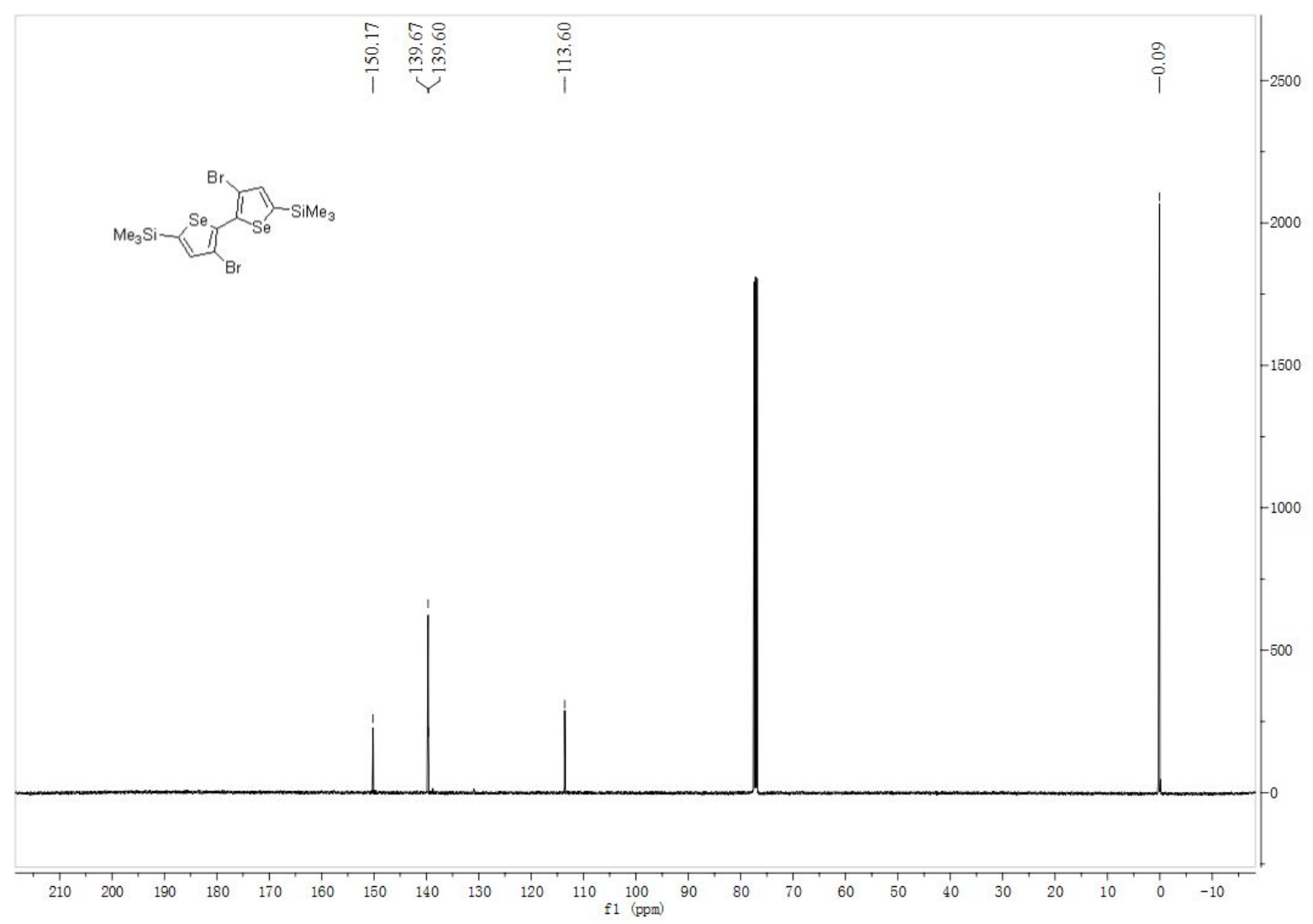

Figure S23. ${ }^{13} \mathrm{C}$ NMR spectrum of compound 7 (r.t., in $\mathrm{CDCl}_{3}$ ). 


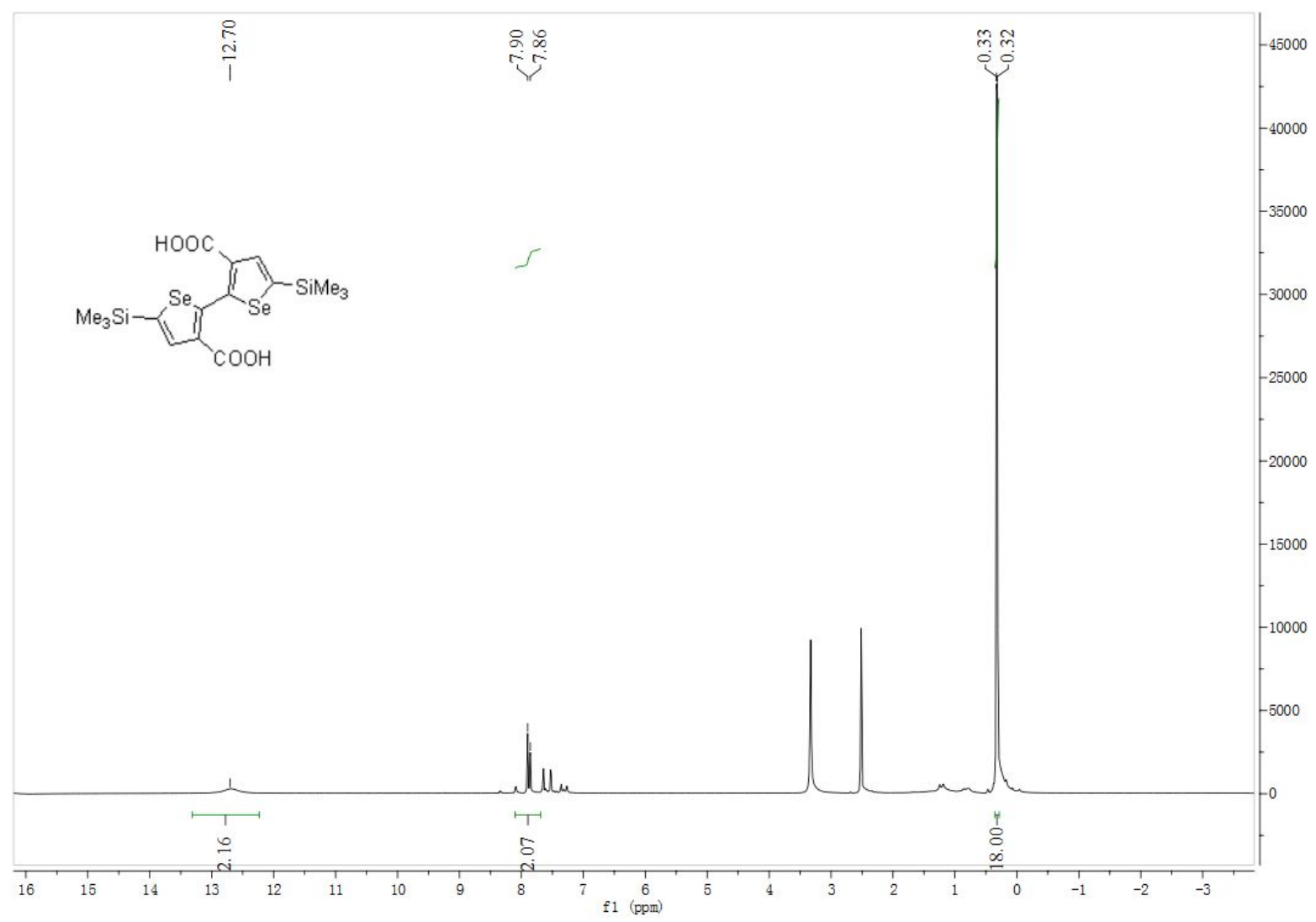

Figure S24. ${ }^{1} \mathrm{H}$ NMR spectrum of compound 8 (r.t., in DMSO- $d_{6}$ ).

T: FTMS - p ESI Full ms [100.0000-1500.0000]

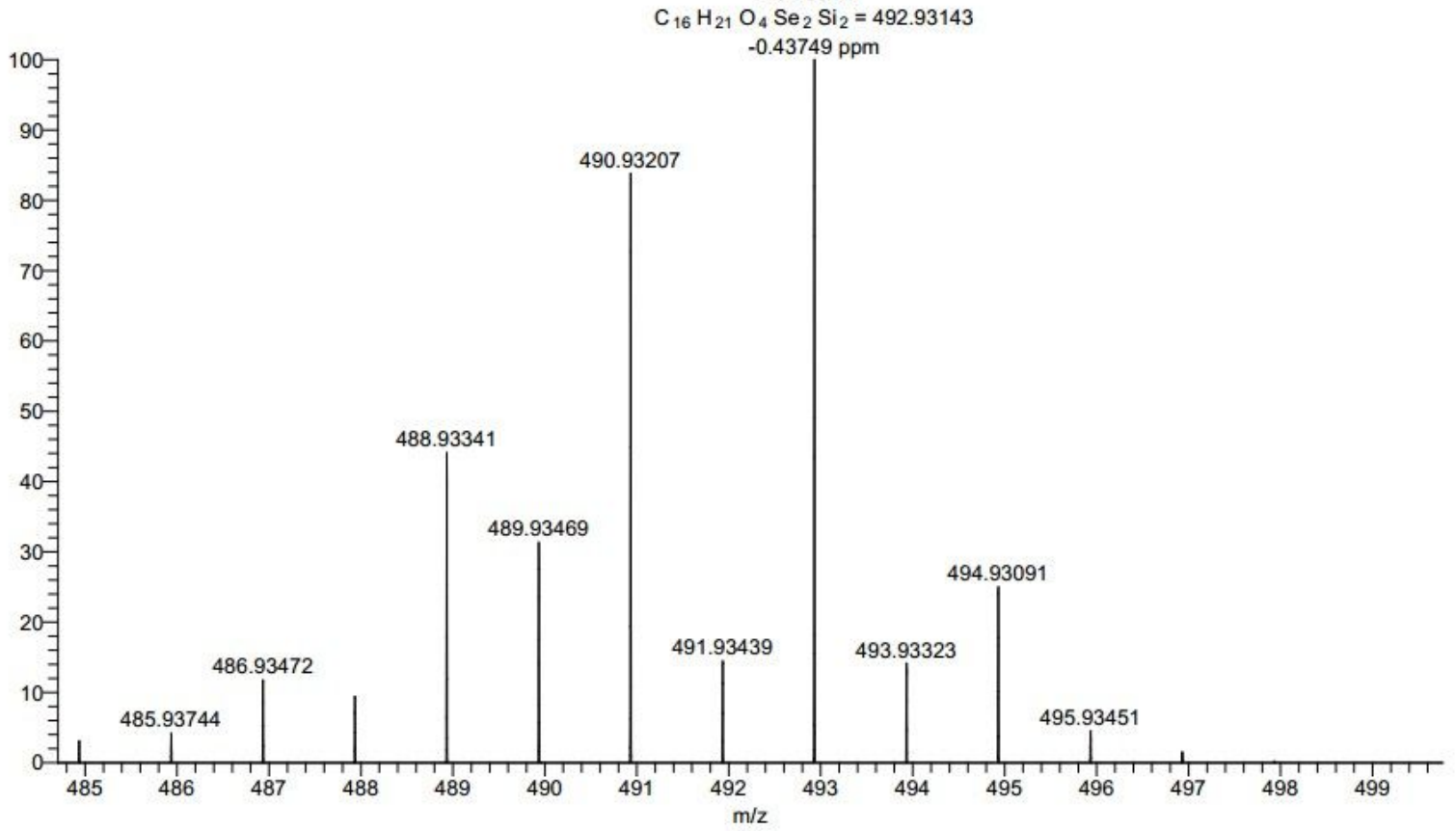

Figure S25. HRMS spectrum of compound $\mathbf{8}$. 


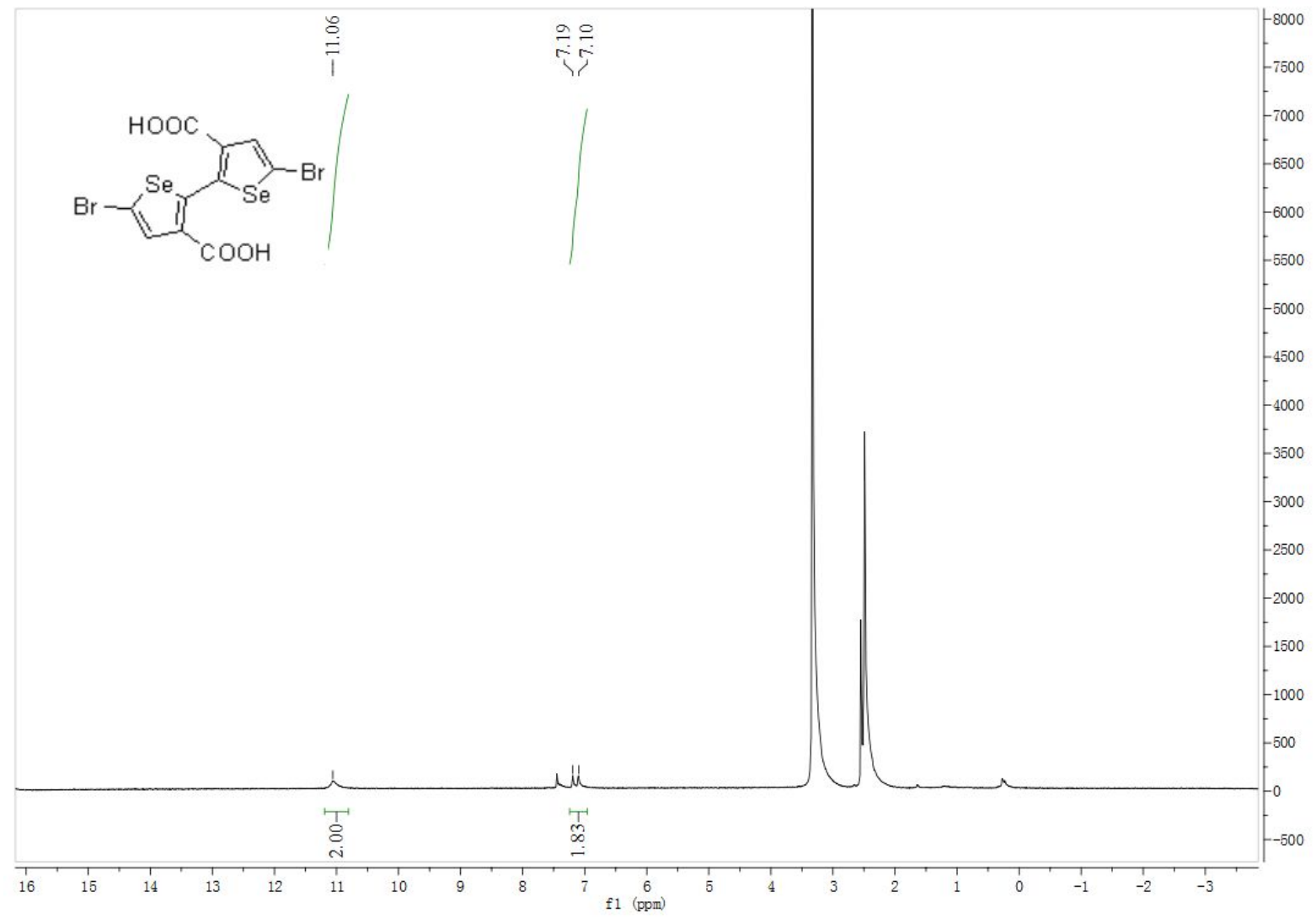

Figure S26. ${ }^{1} \mathrm{H}$ NMR spectrum of compound 9 (r.t., in DMSO- $d_{6}$ ).

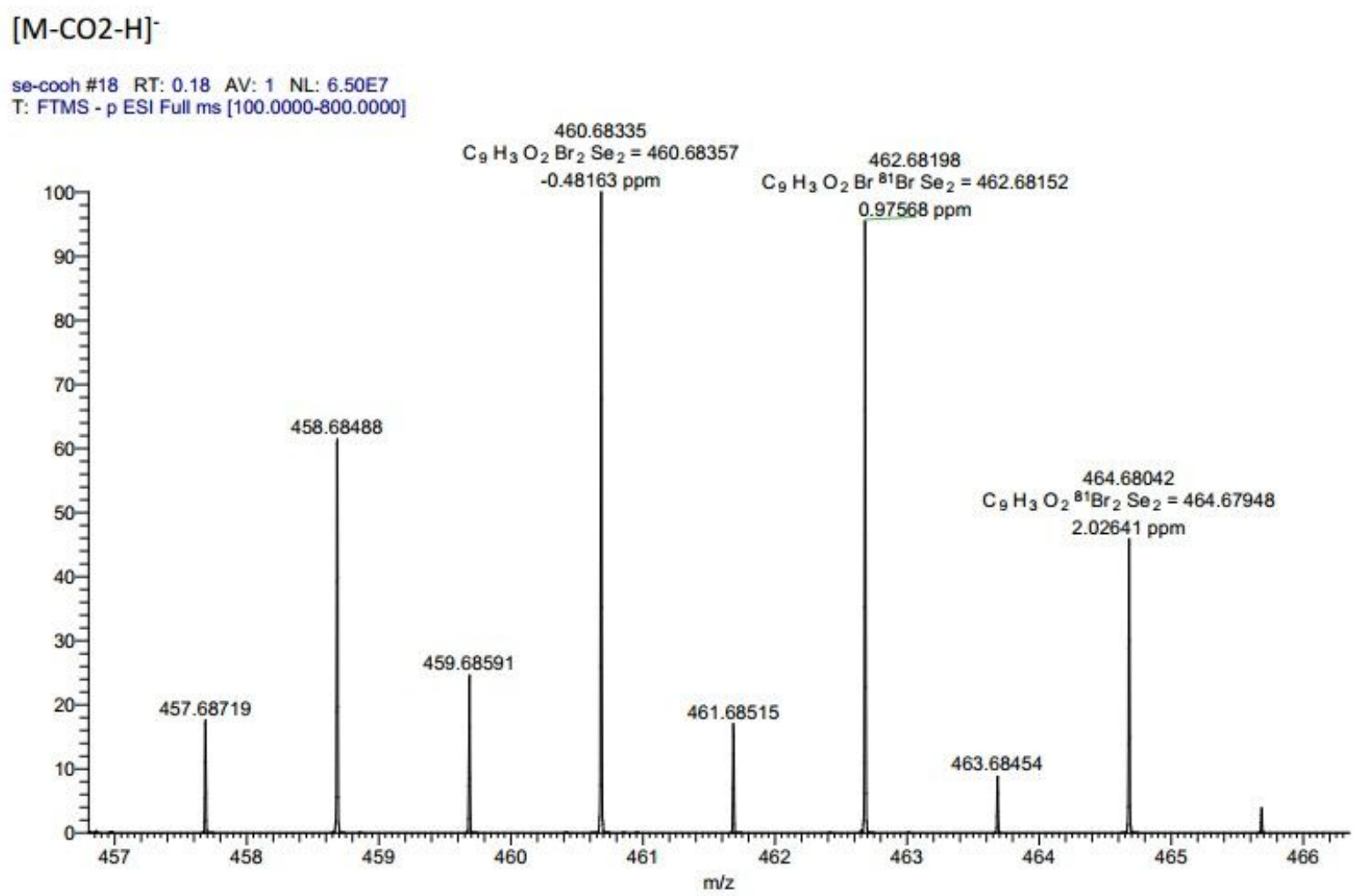

Figure S27. HRMS spectrum of compound 9. 


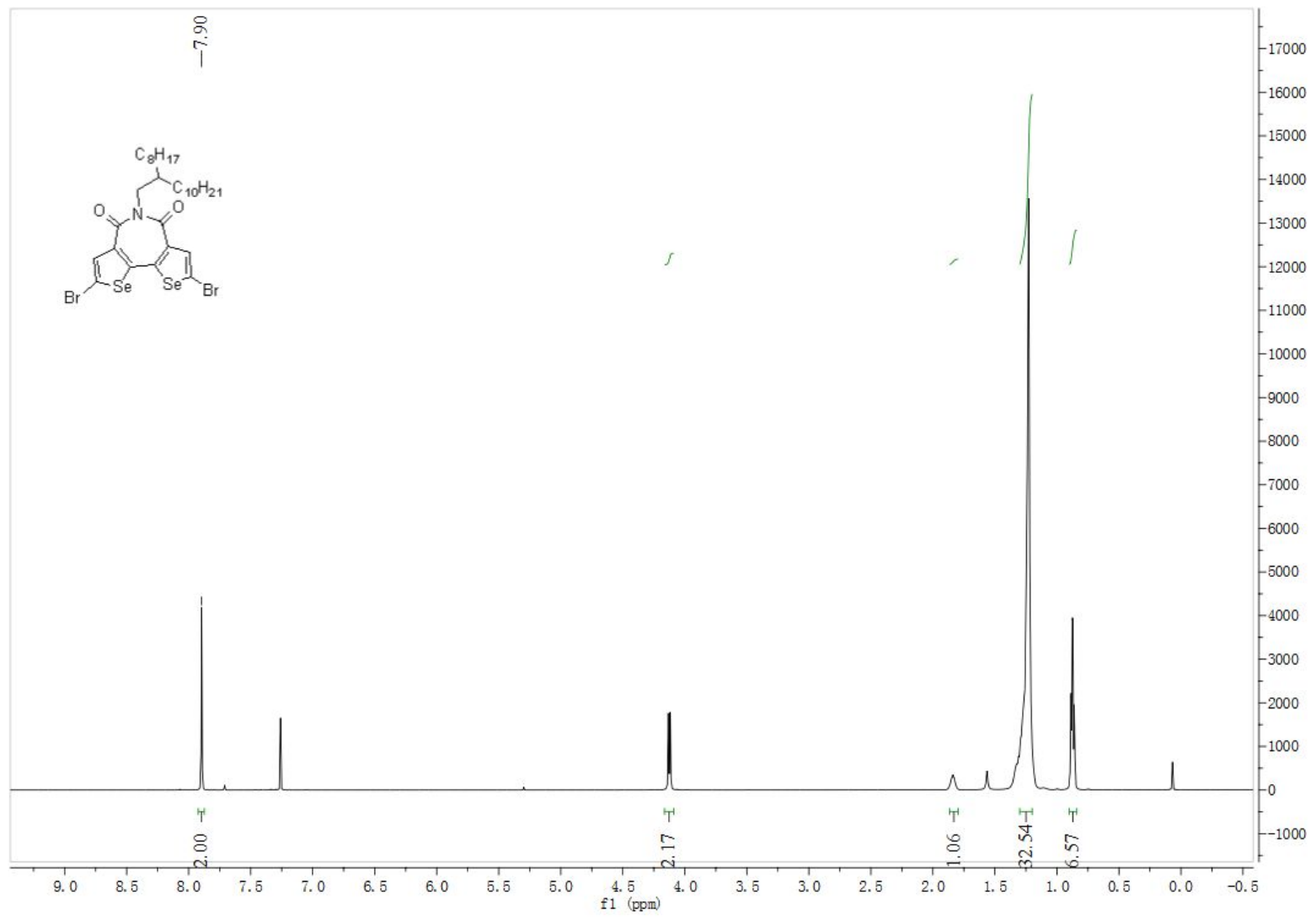

Figure S28. ${ }^{1} \mathrm{H}$ NMR spectrum of dibrominated monomer BSeI-Br (r.t., in $\mathrm{CDCl}_{3}$ ).

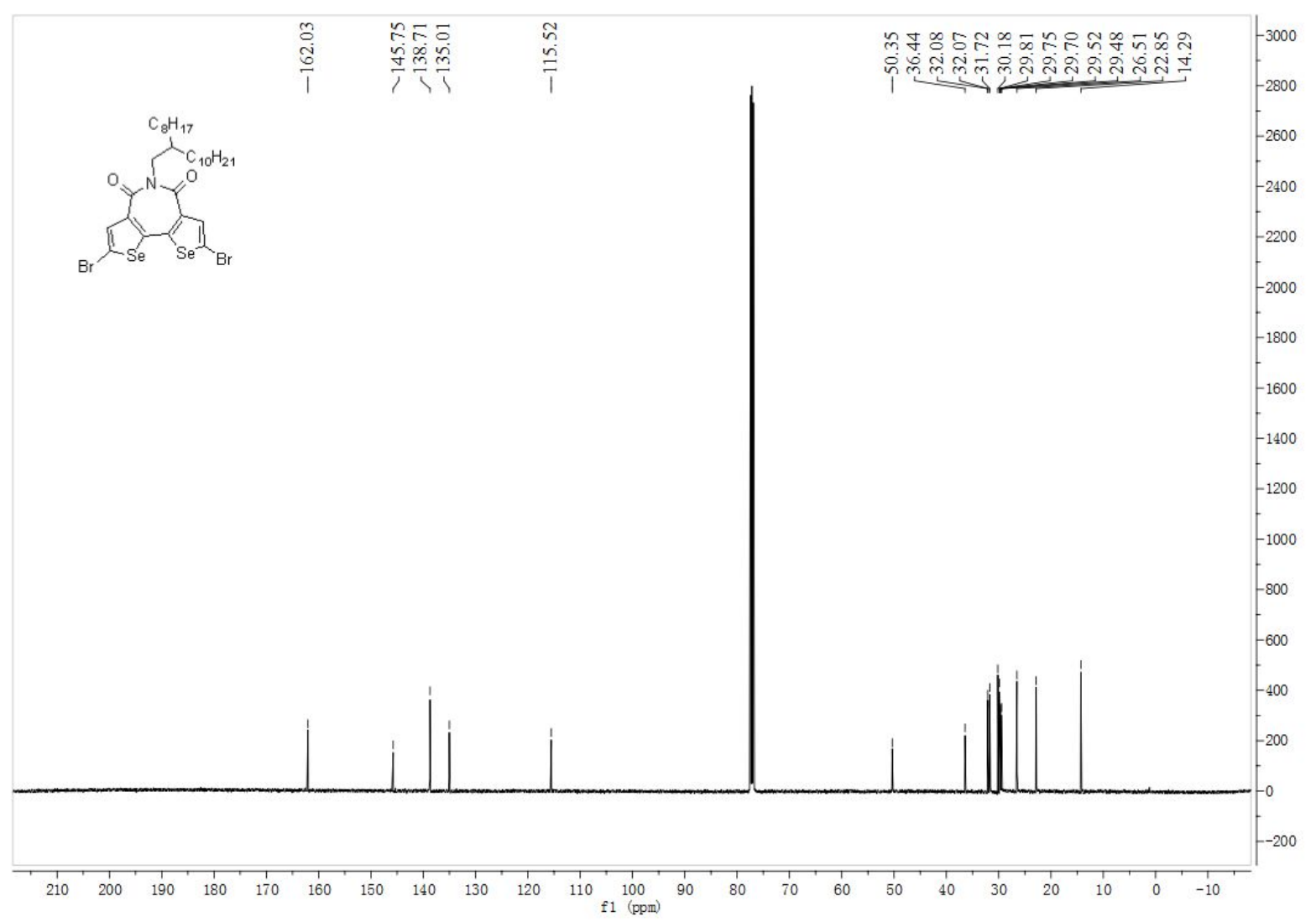

Figure S29. ${ }^{13} \mathrm{C}$ NMR spectrum of dibrominated monomer BSeI-Br (r.t., in $\mathrm{CDCl}_{3}$ ). 
Se \#16 RT: 0.17 AV: 1 NL: $1.14 E 7$

T: FTMS + p ESI Full ms [100.0000-800.0000]

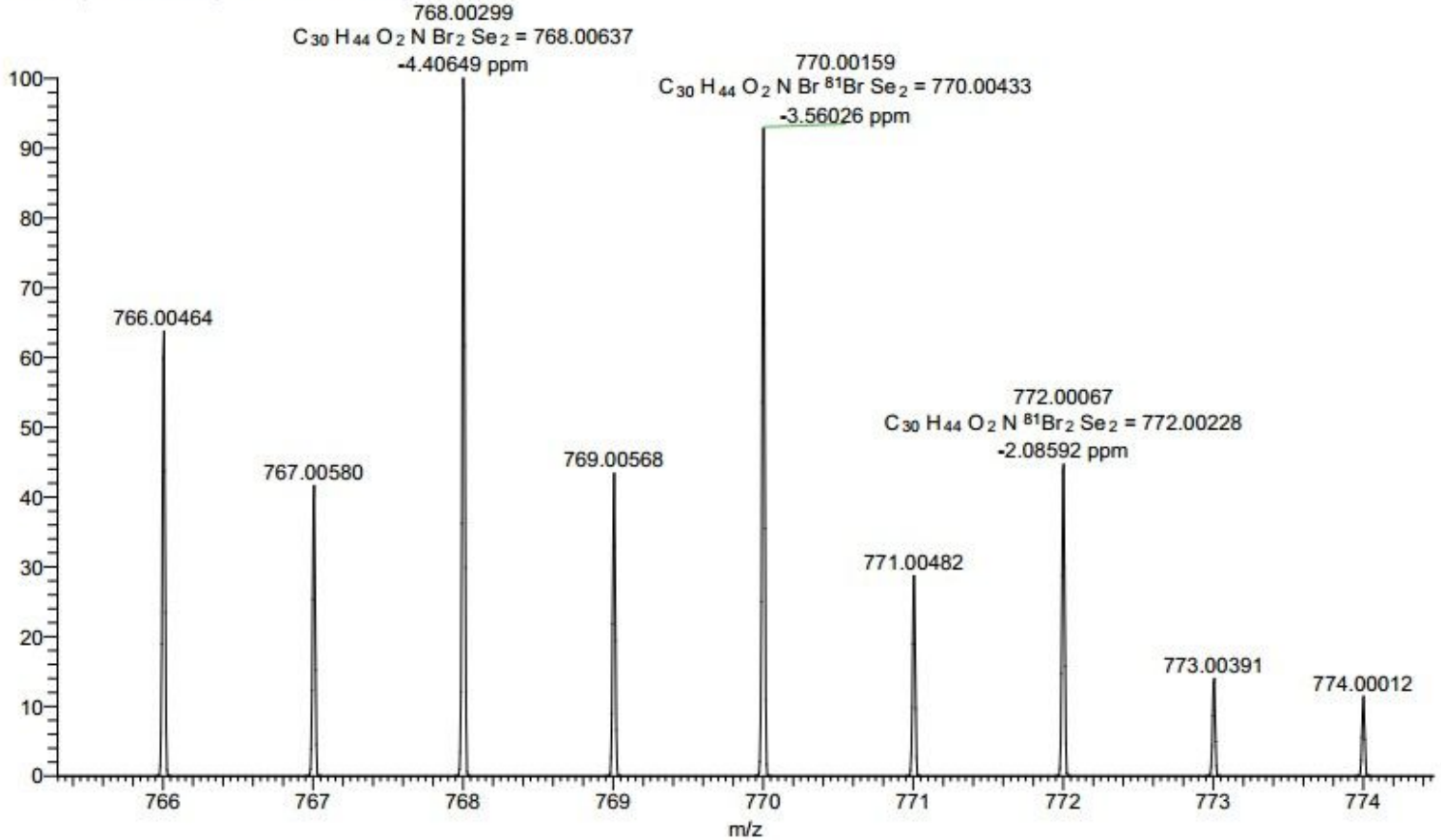

Figure S30. HRMS spectrum of dibrominated monomer BSeI-Br.

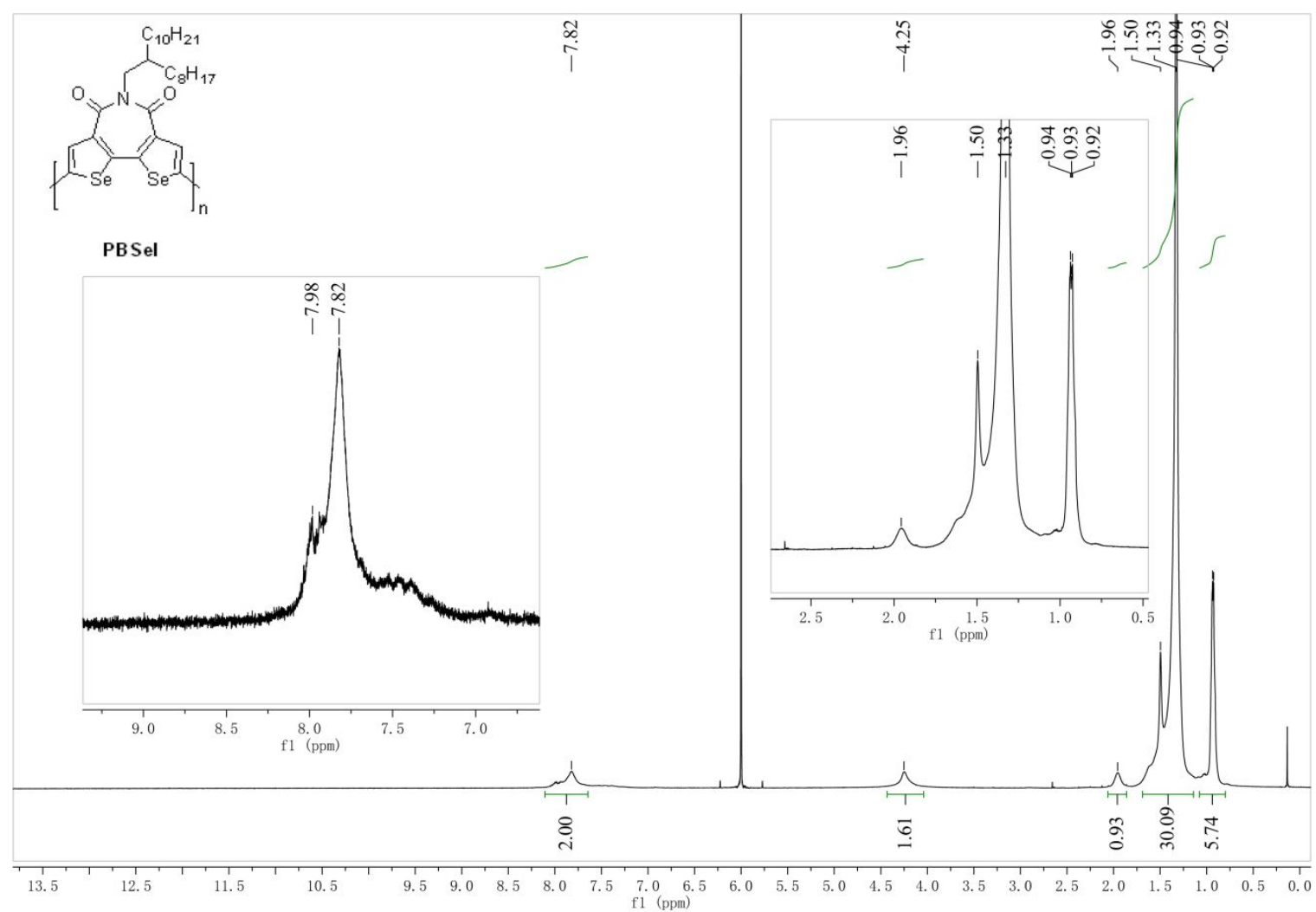

Figure S31. ${ }^{1} \mathrm{H}$ NMR spectrum of polymer PBSeI $\left(80{ }^{\circ} \mathrm{C}\right.$ in $\left.\mathrm{C}_{2} \mathrm{D}_{2} \mathrm{Cl}_{4}\right)$. 


\section{References}

(1) Jin, X. H.; Sheberla, D.; Shimon, L. J.; Bendikov, M. Highly Coplanar Very Long Oligo(alkylfuran)s: A Conjugated System with Specific Head-to-Head Defect. J. Am. Chem. Soc. 2014, 136, 2592-2601.

(2) Guo, X.; Ortiz, R. P.; Zheng, Y.; Hu, Y.; Noh, Y.-Y.; Baeg, K.-J.; Facchetti, A.; Marks, T. J. Bithiophene-Imide-Based Polymeric Semiconductors for Field-Effect Transistors: Synthesis, Structure-Property Correlations, Charge Carrier Polarity, and Device Stability. J. Am. Chem. Soc. 2011, 133, 1405-1418.

(3) Wang, Y.; Guo, H.; Harbuzaru, A.; Uddin, M. A.; Arrechea-Marcos, I.; Ling, S.; Yu, J.; Tang, Y.; Sun, H.; López Navarrete, J. T.; Ortiz, R. P.; Woo, H. Y.; Guo, X. (Semi)ladder-Type Bithiophene Imide-Based All-Acceptor Semiconductors: Synthesis, Structure-Property Correlations, and Unipolar n-Type Transistor Performance. J. Am. Chem. Soc. 2018, 140, 6095-6108.

(4) Xu, W.; Wu, L.; Fang, M.; Ma, Z.; Shan, Z.; Li, C.; Wang, H. Diseleno[2,3-b:3',2'-d]selenophene and Diseleno[2,3-b:3',2'-d] thiophene: Building Blocks for the Construction of [7]Helicenes. J. Org. Chem. 2017, 82 (20), 11192-11197..

(5) Fei, Z.; Han, Y.; Gann, E.; Hodsden, T.; Chesman, A. S. R.; McNeill, C. R.; Anthopoulos, T. D.; Heeney, M. Alkylated Selenophene-Based Ladder-Type Monomers via a Facile Route for High-Performance Thin-Film Transistor Applications. J. Am. Chem. Soc. 2017, 139, 8552-8561.

(6) Getmanenko, Y. A.; Tongwa, P.; Timofeeva, T. V.; Marder, S. R. Base-Catalyzed Halogen Dance Reaction and Oxidative Coupling Sequence as a Convenient Method for the Preparation of Dihalo-bisheteroarenens. Org. Lett. 2010, 12, 2136-2139.

(7) Letizia. J. A.; Salata. M.R.; Tribout. C. M.; Facchetti. A.; Ratner. A. R.; Marks. T. J. n-Channel Polymers by Design: Optimizing the Interplay of Solubilizing Substituents, Crystal Packing, and Field-Effect Transistor Characteristics in Polymeric Bithiophene-Imide Semiconductors. J. Am. Chem. Soc. 2008, 130, 9679-9694.

(8) Shi, Y.; Guo, H.; Qin. M.; Zhao, J.; Wang, Y.; Wang, H.; Wang, Y.; Facchetti, A.; Lu, X.; Guo, X. Thiazole Imide-Based All-Acceptor Homopolymer: Achieving High-Performance Unipolar Electron Transport in Organic Thin-Film Transistors. Adv. Mater. 2018, 1705745. 